\title{
Molecular volumes of phospholipids and glycolipids in membranes
}

\author{
Derek Marsh* \\ Max-Planck-Institut für biophysikalische Chemie, Abt. Spektroskopie, 37070 Göttingen, Germany
}

\section{A R T I C L E I N F O}

\section{Article history:}

Received 22 February 2010

Received in revised form 17 June 2010

Accepted 17 June 2010

Available online 25 June 2010

\section{Keywords:}

Dilatometry

Densitometry

Partial specific volume

Phospholipids

Glycolipids

\begin{abstract}
A B S T R A T
Data on the molecular volumes of phospholipids and glycolipids in membranes are collected together in order to determine the contributions from the component groups, for as wide a range of lipids as possible, including sphingolipids. Wherever possible, the volumes of the methylene groups in the lipid chains are established from the dependence on chain length at fixed temperature in a given phase. In this way, it is also possible to determine the constant contribution from cis double bonds in the chains of monoenoic unsaturated phosphatidylcholines, and the volume of the branched methyl groups in isoacyl phosphatidylcholines. Issues concerning separation of contributions from the polar head groups from those of the chain terminal methyl groups are discussed. Molecular volumes of lipids in crystals are also analysed to provide information on head-group packing that can be compared with the situation in membranes, and used to set limits on the relative contributions from polar groups and terminal methyl groups. Comparisons are made with volumetric analyses based on diffraction studies of bilayers of single lipids. The parameters derived can be used to estimate molecular volumes of lipids for which dilatometric or densitometric data are lacking. Lipid volumes are determining parameters for lipid dynamics, membrane partitioning and permeation of solutes, and are essential quantities for the structural analysis of lipid membranes.
\end{abstract}

(c) 2010 Elsevier Ireland Ltd. All rights reserved.

\section{Introduction}

The volume that is occupied by each of the lipid molecules is one of the most fundamental properties of the lipid bilayer membrane. Its size, relative to the true van der Waals volume, determines the free volume of the membrane, which in turn regulates dynamic processes such as translational diffusion, the partitioning of hydrophobic molecules (including drugs and anaesthetics) into the membrane, and the permeability of the lipid membrane to solutes. In addition, the molecular volume is an essential parameter for structural determinations in membranes. It is required to obtain the bilayer thickness from X-ray measurements of the bilayer repeat distance in hydrated multilamellae (Luzzati, 1968). At a more detailed level of structural analysis, it determines electron or scattering-length densities that are needed for interpreting X-ray and neutron scattering experiments and for analysing form factors obtained by diffraction methods (Wiener et al., 1989; Kucerka et al., 2004, 2005a).

The basic quantity that is needed to determine the molecular volume of a lipid in a membrane is the partial specific volume, $\bar{v}_{1}$, which is defined by the increase in volume $V$ of an aqueous

\footnotetext{
* Tel.: +49 551201 1285; fax: +495512011501

E-mail address: dmarsh@gwdg.de.
}

dispersion on adding lipid:

$\bar{v}_{1}=\left(\frac{\partial V}{\partial m_{1}}\right)_{T, P, m_{\mathrm{w}}}$

where $m_{1}$ is the mass of lipid and $m_{\mathrm{w}}$ that of the water present. The change in volume of the dispersion also involves any apparent change in volume of the water which hydrates the lipid head groups. The apparent volume of a lipid molecule in a membrane is related to the lipid partial specific volume, $\bar{v}_{1}$, by:

$v_{\mathrm{mol}}=\frac{M_{1} \bar{v}_{\mathrm{l}}}{N_{\mathrm{A}}}$

where $M_{1}$ is the molecular weight of the lipid and $N_{\mathrm{A}}$ is Avogadro's number. An alternative definition is the partial molar volume, which is given by: $V_{\mathrm{m}}=M_{1} \bar{v}_{1}$. As already noted, both quantities include any volume changes that are associated with hydration of the lipid head groups. For comparison, the volume of a lipid molecule in a crystal is related to the dimensions $a, b$ and $c$ of the unit cell by:

$v_{\mathrm{mol}}=a b c \frac{\sqrt{1-\cos ^{2} \alpha-\cos ^{2} \beta-\cos ^{2} \gamma+2 \cos \alpha \cos \beta \cos \gamma}}{Z}$

where $\alpha, \beta$ and $\gamma$ are the angles between the unit cell axes and $Z$ is the number of lipid molecules in the unit cell. Note that not all lipid crystals are orthorhombic (for which $\alpha=\beta=\gamma=90^{\circ}$, and $v_{\text {mol }}=$ $a b c / Z$ ). The definition in Eq. (3) includes any solvent molecules of 


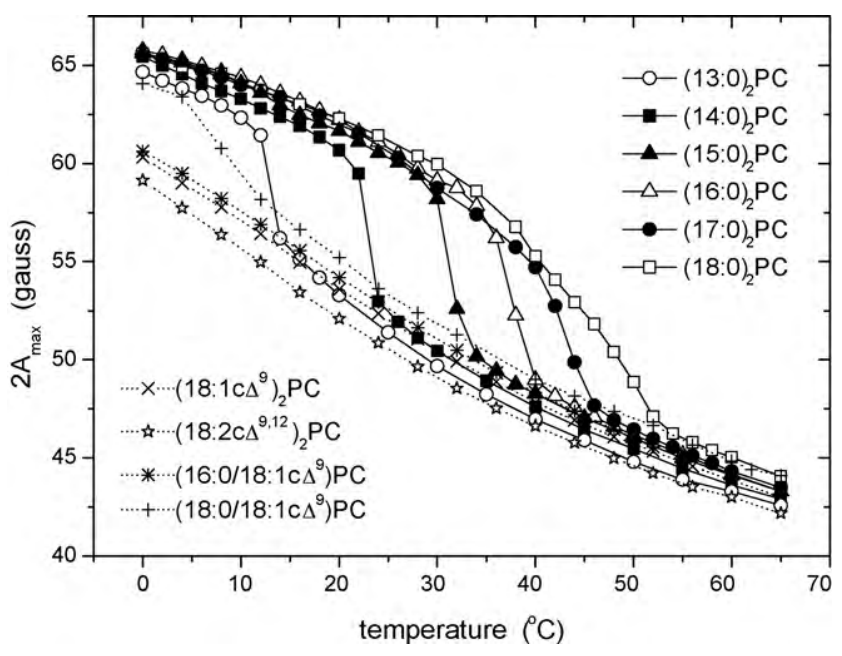

Fig. 1. Temperature dependence of the outer hyperfine splitting, $2 A_{\max }$, of phosphatidylcholine spin-labelled on the $5 \mathrm{C}$-atom of the $s n-2$ chain $(0.5 \mathrm{~mol} \%)$ in hydrated bilayers of saturated diacyl phosphatidylcholines, $(n: 0)_{2} \mathrm{PC}$, and unsaturated diacyl phosphatidylcholines, $(n: 1,2)_{2} \mathrm{PC},\left(n_{1}: 0 / n_{2}: 1\right) \mathrm{PC}$. Phospholipids were obtained from Avanti Polar Lipids (Alabaster, AL.); spin label was synthesised as described (Marsh and Watts, 1982; Marsh, 2009). For details of sample preparation and EPR spectroscopy, see (Rama Krishna and Marsh, 1990; Bartucci et al., 1993; Schorn and Marsh, 1996a).

crystallisation, the volume of which must be subtracted to give the bare lipid volume that is comparable to the definition derived from the partial specific volume and given by Eq. (2).

\section{Reference temperature}

Combination of volumetric data from lipids of the same species but different chain lengths requires a choice of the appropriate reference temperature. Potential candidates are the same absolute temperature (see e.g., Nagle and Wiener, 1988), or comparable temperatures relative to the chain-melting transition, i.e., the same reduced temperature (see e.g., Small, 1986).

Fig. 1 shows the temperature dependence of the outer hyperfine splitting, $2 A_{\max }$, from a phosphatidylcholine spin probe in hydrated bilayers of saturated diacyl phosphatidylcholines with different chain lengths in the range $n=13-18 \mathrm{C}$-atoms, and also of unsaturated diacyl phosphatidylcholines with symmetrical or mixed chains. The spin-label moiety is attached at C-5 of the sn2 chain. The outer hyperfine splitting depends on the amplitude, and also rate, of angular motion of the spin-labelled chain segment (Lange et al., 1985; Moser et al., 1989; Schorn and Marsh, 1996b). It is therefore a useful parameter for characterising chain dynamics in both gel and fluid membrane phases (Rama Krishna and Marsh, 1990; Bartucci et al., 1993; Schorn and Marsh, 1996a), and depends directly on the available free volume within the lipid bilayer. Lower values of $A_{\max }$ correspond to higher amplitudes and/or rates of chain rotation, and hence to larger free volumes. This is seen clearly from the abrupt decrease in $A_{\max }$ that occurs on chain melting of the bilayers of the different-chainlength phosphatidylcholines at their corresponding gel-to-fluid transition temperatures. However, the sensitivity is much less in the gel phase than it is in the fluid phase, because the former corresponds to the slow-motion regime of conventional spin-label EPR spectroscopy, whereas the latter lies in the fast-motional regime.

Although the EPR splittings depend on other factors in addition to free volume, the results of Fig. 1 clearly indicate that the lipid bilayers are in equivalent states at the same absolute, rather than reduced, temperature. The values of $A_{\max }$ are comparable for all chain lengths at the same temperature when in

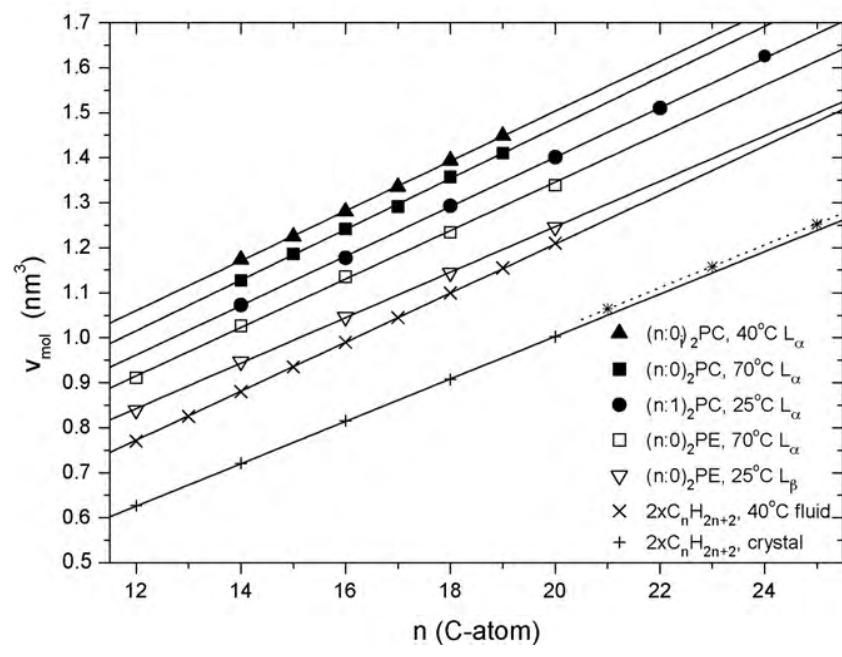

Fig. 2. Lipid molecular volume as a function of acyl chain length, $n$. Saturated straight-chain diacyl phosphatidylcholines $(n: 0)_{2} \mathrm{PC}$ in the $\mathrm{L}_{\alpha}$ phase at $70^{\circ} \mathrm{C}$ (solid squares; Schmidt and Knoll, 1985); monoenoic diacyl phosphatidylcholines $(n: 1)_{2} \mathrm{PC}$ in the $\mathrm{L}_{\alpha}$ phase at $25^{\circ} \mathrm{C}$ (solid circles; Uhríková et al., 2007); branchedchain di-isoacyl phosphatidylcholines $\left(n: 0_{i}\right)_{2} \mathrm{PC}$ in the $\mathrm{L}_{\alpha}$ phase corrected to $40{ }^{\circ} \mathrm{C}$ (solid triangles; Yang et al., 1986); saturated straight-chain diacyl phosphatidylethanolamines $(n: 0)_{2} \mathrm{PE}$ in the $\mathrm{L}_{\alpha}$ phase corrected to $70{ }^{\circ} \mathrm{C}$ (open squares; Koynova and Hinz, 1990; Seddon et al., 1984) and in the $\mathrm{L}_{\beta}$ phase corrected to $25^{\circ} \mathrm{C}$ (open inverted triangles; Koynova and Hinz, 1990; Seddon et al., 1984); straightchain alkanes $\mathrm{C}_{n} \mathrm{H}_{2 n+2}$ in the liquid state at $40{ }^{\circ} \mathrm{C}$ ( $\times$; Rossini et al., 1953) and in the crystalline state (+ even $n$; Nyburg et al., 1976; Müller and Lonsdale, 1948; Crissman et al., 1970; * odd $n$; Smith, 1953). Note: $n$ for di-isoacyl PCs excludes the branched methyl group.

a given phase (gel or fluid), but are larger for the lower-melting lipids at a given temperature difference from the chain-melting transition. This is not a phenomenon that is restricted to phosphatidylcholines; similar EPR results have been found with bilayers of biotinylphosphatidylethanolamines (Swamy and Marsh, 1994). Thus, the appropriate reference temperature for comparing data on lipid molecular volumes is the same absolute temperature, irrespective of chain-melting temperature (except that the lipids must be in the same phase).

The above conclusion was reached previously by Wiener and White (1992) from neutron diffraction experiments on fluidphase dioleoyl phosphatidylcholine bilayers. The ratio of methyl to methylene volumes was found to be approximately two, a result that is obtained for liquid alkanes when comparison is made at the same absolute temperature, but not when made at the same reduced temperature. The ratio of two is also obtained in molecular dynamics simulations of dioleoyl phosphatidylcholine bilayers, demonstrating that this experimental feature can be reproduced by simulations (Armen et al., 1998). Additionally, Nagle and Wiener (1988) have argued on theoretical grounds that absolute temperature is the appropriate reference state. This is the approach that will be adopted here.

\section{Phospholipids}

\subsection{Chain-length dependence and $\mathrm{CH}_{2}$ volume}

Fig. 2 shows the dependence of the lipid molecular volume, $v_{\text {mol }}$, on length, $n$, of the hydrocarbon chains. Data are given for the phospholipids phosphatidylcholine (PC) and phosphatidylethanolamine (PE), and for saturated straight-chain $n$-alkanes $\left(\mathrm{C}_{n} \mathrm{H}_{2 n+2}\right)$. For a given lipid, measurements either are at the same temperature in the same phase, or are corrected to the same temperature by using the volume expansion coefficient in 
Table 1

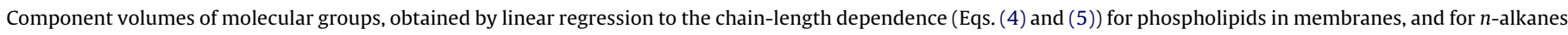
(see Fig. 2).

\begin{tabular}{|c|c|c|c|c|c|c|c|}
\hline \multirow[t]{2}{*}{ Lipid } & \multirow[t]{2}{*}{ Phase } & \multirow[t]{2}{*}{$T\left({ }^{\circ} \mathrm{C}\right)$} & \multicolumn{2}{|l|}{$v_{\mathrm{CH}_{2}}$} & \multicolumn{2}{|l|}{$v_{\text {end }^{\mathrm{a}}}$} & \multirow[t]{2}{*}{ Ref. $^{b}$} \\
\hline & & & $\left(\mathrm{nm}^{3}\right)$ & $(\mathrm{ml} / \mathrm{mol})$ & $\left(\mathrm{nm}^{3}\right)$ & $(\mathrm{ml} / \mathrm{mol})$ & \\
\hline$(n: 0)_{2} \mathrm{PC}$ & $\mathrm{L}_{\alpha}$ & 70 & $0.0282 \pm 0.0004$ & $17.0 \pm 0.2$ & $0.451 \pm 0.012$ & $272 \pm 7$ & 1 \\
\hline$(n: 1)_{2} \mathrm{PC}$ & $\mathrm{L}_{\alpha}$ & 25 & $0.0275 \pm 0.0002$ & $16.6 \pm 0.1$ & $0.522 \pm 0.005$ & $314 \pm 3$ & 2 \\
\hline$\left(n: 0_{i}\right)_{2} P C$ & $\mathrm{~L}_{\alpha}$ & 40 & $0.0277 \pm 0.0003$ & $16.7 \pm 0.2$ & $0.506 \pm 0.007^{c}$ & $305 \pm 4^{\mathrm{c}}$ & 3 \\
\hline \multirow[t]{2}{*}{$(n: 0)_{2} \mathrm{PE}$} & $\mathrm{L}_{\alpha}$ & 70 & $0.0269 \pm 0.0007$ & $16.2 \pm 0.4$ & $0.376 \pm 0.017$ & $227 \pm 11$ & 4 \\
\hline & $\mathrm{L}_{\beta}$ & 25 & $0.0253 \pm 0.0002$ & $15.2 \pm 0.1$ & $0.337 \pm 0.007$ & $203 \pm 4$ & 4,5 \\
\hline \multirow[t]{4}{*}{$n-\mathrm{C}_{n} \mathrm{H}_{2 n+2}$} & Liquid $^{\mathrm{d}}$ & 40 & $0.02739 \pm 0.00003$ & $16.49 \pm 0.02$ & $0.1117 \pm 0.0003$ & $67.2 \pm 0.2$ & 6 \\
\hline & & 70 & $0.02783 \pm 0.00004$ & $16.76 \pm 0.03$ & $0.1194 \pm 0.0005$ & $71.9 \pm 0.3$ & 6 \\
\hline & Crystal, even $n^{\mathrm{e}}$ & - & $0.0236 \pm 0.0001$ & $14.20 \pm 0.06$ & $0.0769 \pm 0.0013$ & $46.3 \pm 0.8$ & $7-9$ \\
\hline & Crystal, odd $n^{\mathrm{f}}$ & - & $0.0237 \pm 0.0001$ & $14.29 \pm 0.05$ & $0.0810 \pm 0.0018$ & $48.8 \pm 1.1$ & 10 \\
\hline
\end{tabular}

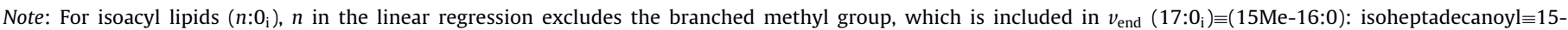
methylhexadecanoyl.

a Total volume of all molecular groups other than the chain methylenes: $v_{\text {end }}$ (diacyl) $=v_{\text {pol }}+n_{\mathrm{CH}} v_{\mathrm{CH}}+2 v_{\mathrm{CH}_{3}}$ (except for branched-chains, see footnote c), and $v_{\mathrm{end}}($ alkane) $=$ $2 v_{\mathrm{CH}_{3}}$.

b References: 1. Schmidt and Knoll, 1985; 2. Uhríková et al., 2007; 3. Yang et al., 1986; 4. Koynova and Hinz, 1990; 5. Seddon et al., 1984; 6. Rossini et al., 1953; 7. Nyburg et al., 1976; 8. Müller and Lonsdale, 1948; 9. Crissman et al., 1970; 10. Smith, 1953.

$c$ Includes the two branched methyl groups and H-atom deficit of the methylenes to which they are attached.

d 14 values in the range $n=7-20$.

e Triclinic crystals: $n=10-20(N=6)$.

f Orthorhombic crystals: $n=21-29(N=5)$.

that particular phase. Under these conditions, the molecular volume depends linearly on chain length, as would be expected if the volumes of the component molecular groups of a diacyl phospholipid are the same at the same temperature in a given phase:

$v_{\text {mol }}($ diacyl $)=n_{\mathrm{CH}_{2}} v_{\mathrm{CH}_{2}}+n_{\mathrm{CH}} v_{\mathrm{CH}}+2 v_{\mathrm{CH}_{3}}+v_{\text {pol }}$

where $n_{\mathrm{CH}_{2}}$ and $v_{\mathrm{CH}_{2}}$ are the number and volume of methylene groups in the chains, $n_{\mathrm{CH}}$ and $v_{\mathrm{CH}}$ are the number and volume of methine groups (unsaturated C-atoms) in the chains, $v_{\mathrm{CH}_{3}}$ is the volume of a terminal methyl group, and $v_{\mathrm{pol}}$ is the volume of the polar head group, which includes the glycerol backbone and chain carbonyls. Eq. (4) applies to all diacyl (and dialkyl) phospholipids and glycolipids, except those with branched chains (see later). For $n$-alkanes, the corresponding expression for the molecular volume is simply:

$v_{\text {mol }}($ alkane $)=n_{\mathrm{CH}_{2}} v_{\mathrm{CH}_{2}}+2 v_{\mathrm{CH}_{3}}$

Volumes of both methylene $\left(v_{\mathrm{CH}_{2}}\right)$ and terminal methyl $\left(v_{\mathrm{CH}_{3}}\right)$ groups can be determined from the linear dependence on chain length that is predicted by Eq. (5) for $n$-alkanes. However, this is not the case for the diacyl lipids. Although $v_{\mathrm{CH}_{2}}$ can be determined unambiguously for diacyl lipids, Eq. (4) indicates that the volume of the terminal methyl groups cannot be determined separately. Only the combined quantity $v_{\text {pol }}+2 v_{\mathrm{CH}_{3}}$ can be obtained from the chainlength dependence of the molecular volume of saturated diacyl (or dialkyl) lipids.

The results of linear regressions to the chain-length dependences of the molecular volumes of various lipids (including those of Fig. 2), at constant temperature in the same phase, are given in Table 1 . In the fluid $\mathrm{L}_{\alpha}$ phase, the effective volume of a methylene group is $v_{\mathrm{CH}_{2}}=0.027-0.028 \mathrm{~nm}^{3}$ depending on temperature and lipid, and is very similar to that in liquid $n$-alkanes. In the $\mathrm{L}_{\beta}$ gel phase of PEs, the volume of a methylene group $\left(v_{\mathrm{CH}_{2}}=\right.$ $\left.0.025 \mathrm{~nm}^{3}\right)$ is less than in the fluid $\mathrm{L}_{\alpha}$ phase, but is slightly larger than in crystalline hydrocarbons $\left(v_{\mathrm{CH}_{2}}=0.024 \mathrm{~nm}^{3}\right)$. It is close to that expected for a gel-phase chain, which has a cross-sectional area of $0.20 \mathrm{~nm}^{2}$ and all-trans segment length of $0.127 \mathrm{~nm}$ (see, e.g., Marsh, 1990). The volume of the methyl groups in liquid $n$ alkanes $\left(v_{\mathrm{CH}_{3}}=0.0559-0.0597 \mathrm{~nm}^{3}\right)$ is $2.04-2.14$ times that of a methylene group, and this ratio increases with increasing temperature. In crystalline $n$-alkanes, for comparison, the volume of the methyl groups $\left(v_{\mathrm{CH}_{3}}=0.038-0.041 \mathrm{~nm}^{3}\right)$ is $1.6-1.7$ times that of a methylene group, where the lower value corresponds to triclinic crystals for even chain lengths $n=10-20$ and the higher value to orthorhombic crystals for odd chain lengths $n=21-29$ (see Table 1 ).

It should be noted that the linear extrapolation works only if the methylene groups occupy the same volume, independent of chain length. For this it is important that the lipids of different chain length be in the same phase and at the same temperature. Even so, there are potential problems in the more condensed phases, if the packing mode changes with chain length. This is the case with the $\mathrm{L}_{\beta^{\prime}}$ phase of saturated phosphatidylcholines, for which the methylene group volume decreases with increasing chain length at constant temperature, an effect that correlates with increasing rhombicity of the chain packing (Sun et al., 1996).

\subsection{Double-bond $\left(v_{\mathrm{CH}}\right)$ and isobranch $\left(v_{i M e}\right)$ volumes}

Comparison of the "end" contributions, $v_{\text {end }}$, in fluid-phase phosphatidylcholines gives estimates of the contributions of branched methyl groups, and of unsaturated bonds, to the lipid volume. Allowance can be made for the different temperatures of measurement by calculating an effective expansion coefficient from the volumes of a methylene group in the various bilayers (see Table 1). This turns out to be $\approx 6 \times 10^{-4} \mathrm{~K}^{-1}$, for both $(n: 1)_{2} \mathrm{PC}$ and $\left(n: 0_{\mathrm{i}}\right)_{2} \mathrm{PC}$ lipids, when referred to the $(n: 0)_{2} \mathrm{PC}$ series. From the data for the $(n: 1)_{2} \mathrm{PC}$ and $(n: 0)_{2} \mathrm{PC}$ series, the volume of each $\mathrm{CH}$ group in the double bonds is then calculated to be $v_{\mathrm{CH}}=0.021 \mathrm{~nm}^{3}$ at $25^{\circ} \mathrm{C}$. For comparison, a value of $v_{\mathrm{CH}}=0.0222 \mathrm{~nm}^{3}$ at $25^{\circ} \mathrm{C}$ was obtained from measurements on unsaturated lipids alone, but with the assumption of a fixed ratio between the volumes of methyl and methylene groups and/or a fixed polar group volume (Uhríková et al., 2007; Koenig and Gawrisch, 2005). In addition, expansion coefficients of 7.1 and $10.0 \times 10^{-4} \mathrm{~K}^{-1}$ were found for the $\mathrm{CH}$-group volume in the latter two references, respectively, i.e., reasonably close to the effective value used here. The effective volume of a $\mathrm{CH}$ group in liquid alkenes is also close to $v_{\mathrm{CH}}=0.021 \mathrm{~nm}^{3}$ (Requena and Haydon, 1975), and that in (18:1) $)_{2}$ PC bilayers at $23^{\circ} \mathrm{C}$ deduced by diffraction methods is $v_{\mathrm{CH}} \approx 0.023 \mathrm{~nm}^{3}$ (Wiener and White, 1992).

Applying a similar procedure to the end contribution for diisoacyl phosphatidylcholines by using data from the $\left(n: 0_{\mathrm{i}}\right)_{2} \mathrm{PC}$ and $(n: 0)_{2}$ PC series, gives a volume contribution of $v_{i \mathrm{Me}}=0.031 \mathrm{~nm}^{3}$ from each methyl branch. Note that $v_{i \mathrm{Me}}$ corresponds to the vol- 
ume of a methyl group minus the single $\mathrm{H}$-atom deficit produced by the methyl substitution, and is therefore formally equivalent to the volume of a methylene group. The volume contribution of methyl branching $v_{\mathrm{iMe}} / v_{\mathrm{CH}_{2}}=1.1$, relative to that of a methylene group, is therefore reasonable and compares well with the value of 1.2 that was obtained for this ratio by combining dilatometric and $\mathrm{X}$-ray diffraction measurements solely on the isobranched lipids (Yang et al., 1986). Because, however, both methyl groups are formally equivalent in isoacyl chains, the effective volumes of the two should be averaged.

This brings one to the thorny problem of separating the contribution to $v_{\text {end }}$ of the terminal methyl groups, $2 v_{\mathrm{CH}_{3}}$, from that of the polar groups, $v_{\text {pol }}$. Before attempting this, it is helpful to consider the molecular volumes in phospholipid crystals.

\subsection{Phospholipid crystal volumes}

Molecular volumes obtained from the unit cell dimensions of crystalline lipids are given in Table 2 . Where solvent molecules cocrystallise with the lipid, the volumes of these molecules have been subtracted to give the net lipid volume, as indicated in the footnotes. It should be mentioned that not all structures correspond to the same conformation or packing of the lipid molecules (Pascher et al., 1992; Marsh and Páli, 2006). For instance, those of (12:0) ${ }_{2}$ PEMe,

Table 2

Molecular volumes in phospholipid crystals.

\begin{tabular}{|c|c|c|c|}
\hline Lipid $^{\mathrm{a}}$ & $v_{\mathrm{mol}}\left(\mathrm{nm}^{3}\right)$ & $v_{\mathrm{pol}}\left(\mathrm{nm}^{3}\right)$ & Ref. $^{\text {b }}$ \\
\hline$(14: 0)_{2} \mathrm{PC}^{\mathrm{c}}$ & 1.008 & 0.362 & $1 ; 2$ \\
\hline$(0-18: 0 / 0-1: 0) P^{d}$ & $0.8513 \pm 0.0007$ & $0.3702 \pm 0.0007$ & 3 \\
\hline$(12: 0)$ deoxyLPC $^{d}$ & $0.608 \pm 0.005$ & $0.332 \pm 0.005$ & 4 \\
\hline$(16: 0 / 0: 0) P^{d}$ & $0.7677 \pm 0.0013$ & $0.3970 \pm 0.0013$ & 1 \\
\hline$(0-16: 0 / 0: 0) P C^{e}$ & $0.7146 \pm 0.0011$ & $0.3203 \pm 0.0011$ & 1 \\
\hline$(12: 0)_{2} P^{f}$ & $0.814 \pm 0.011$ & $0.262 \pm 0.011$ & 5 \\
\hline$(16: 0 / 0: 0) \mathrm{PE}$ & $0.645 \pm 0.003$ & $0.274 \pm 0.003$ & 6 \\
\hline$(12: 0)_{2}$ PEMe & $0.8521 \pm 0.0008$ & $0.3000 \pm 0.0008$ & 1 \\
\hline$(12: 0)_{2} \mathrm{PEMe}_{2}$ & $0.8981 \pm 0.0008$ & $0.3460 \pm 0.0008$ & 7 \\
\hline$(16: 0 / 0: 0) \mathrm{PEMe}_{2}$ & $0.6946 \pm 0.0005$ & $0.3240 \pm 0.0005$ & 1 \\
\hline$(14: 0)_{2} \mathrm{PG}^{\mathrm{g}}$ & $0.993 \pm 0.002$ & $0.346 \pm 0.002$ & 8 \\
\hline$(12: 0)_{2} \mathrm{PA}^{\mathrm{h}}$ & $0.7807 \pm 0.0007$ & $0.2287 \pm 0.0007$ & 1 \\
\hline$(14: 0)_{2} \mathrm{PA}^{\mathrm{g}}$ & $0.864 \pm 0.003$ & $0.217 \pm 0.003$ & 9 \\
\hline$(12: 0 / 0: 0) \mathrm{PA}^{\mathrm{i}}$ & $0.4682 \pm 0.0005$ & $0.1921 \pm 0.0005$ & 10 \\
\hline $14: 0 / \mathrm{PA} / 0: 0^{\mathrm{g}}$ & $0.5534 \pm 0.0005$ & $0.2301 \pm 0.0005$ & 1 \\
\hline$(0-16: 0)$ deoxyLPA $1^{d}$ & $0.5493 \pm 0.0008$ & $0.1549 \pm 0.0008$ & 11 \\
\hline$(0-16: 0)$ deoxyLPA2 $^{d}$ & $0.5624 \pm 0.0014$ & $0.1681 \pm 0.0014$ & 11 \\
\hline$(12: 0)_{2} \mathrm{DG}$ & $0.708 \pm 0.002$ & $0.156 \pm 0.002$ & 12 \\
\hline$(16: 0)_{2} \mathrm{DG}$ & $0.893 \pm 0.003$ & $0.151 \pm 0.003$ & 13 \\
\hline
\end{tabular}

a $(14: 0)_{2} \mathrm{PC}, \quad 1,2-(14: 0)_{2} \mathrm{PtdCho} .2 \mathrm{H}_{2} \mathrm{O} ; \quad(0-18: 0 / 0-1: 0) \mathrm{PC}, \quad 1-(0-18: 0)-2-$ (0-1:0)PtdCho. $\mathrm{H}_{2} \mathrm{O}$; (16:0/0:0)PC, 1-(16:0)-2-lysoPtdCho; (12:0)deoxyLPC, 1-(12:0)-2-deoxyPtdCho. $\mathrm{H}_{2} \mathrm{O}$; (O-16:0/0:0)PC, 1-(0-16:0)-2-lysoPtdCho; (12:0 $)_{2} \mathrm{PE}, \quad 1,2-(12: 0)_{2}$ PtdEtn.HAc; $\quad(16: 0 / 0: 0) \mathrm{PE}, \quad$-(16:0)-2-lysoPtdEtn; (12:0) ${ }_{2}$ PEMe, 1,2-(12:0) ${ }_{2}$ Ptd- $N$-MeEtn; $(12: 0)_{2}$ PEMe $_{2}, 1,2-(12: 0)_{2}$ Ptd- $N, N-M_{2}$ Etn; (16:0/0:0)PEMe 2 , 1-(16:0)-2-lysoPtd- $N, N-\mathrm{Me}_{2}$ Etn; (14:0) ${ }_{2} \mathrm{PG}, 1,2-(14: 0)_{2}$ PtdGro; $(12: 0)_{2} \mathrm{PA}, 1,2-(12: 0)_{2} \mathrm{PtdH} ;(14: 0)_{2} \mathrm{PA}, 1,2-(14: 0)_{2} \mathrm{PtdH} ;(12: 0 / 0: 0) \mathrm{PA}, 1-(12: 0)-$ 2-lysoPtdH; (O-16:0)deoxyLPA 1 and 2, 1-(O-16:0)-2-deoxyPtdH; 14:0/PA/0:0, 1-(14:0)-3-lysoPtdH; (12:0) 2 DG, 1,2-(12:0) ${ }_{2}$ Gro; $(16: 0)_{2}$ DG, 1,2-(16:0) $)_{2}$ Gro.

b References: 1. Pascher et al., 1992; 2. Pearson and Pascher, 1979; 3. Pascher et al., 1986; 4. Hauser et al., 1980; 5. Elder et al., 1977; 6. Pascher et al., 1981b; 7. Pascher and Sundell, 1986; 8. Pascher et al., 1987; 9. Harlos et al., 1984; 10. Pascher and Sundell, 1985; 11. Pascher et al., 1984; 12. Pascher et al., 1981a; 13. Dorset and Pangborn, 1988.

c Corrected from dihydrate with $v_{\mathrm{H}_{2} \mathrm{O}}=0.030 \mathrm{~nm}^{3}$.

d Corrected from monohydrate with $v_{\mathrm{H}_{2} \mathrm{O}}=0.030 \mathrm{~nm}^{3}$

e Corrected from chloroform solvate with $v_{\mathrm{CHCl}_{3}}=0.1038 \mathrm{~nm}^{3}$ (Fourmé and Renaud, 1966).

f Corrected from acetic acid solvate with $v_{\mathrm{HAC}}=0.07475 \mathrm{~nm}^{3}$ (Nahringbauer, 1970)

g Corrected from monosodium salt with ionic radius $r_{\mathrm{Na}}=0.097 \mathrm{~nm}$.

h Corrected from monohydrated monosodium salt with $v_{\mathrm{H}_{2} \mathrm{O}}=0.030 \mathrm{~nm}^{3}$ and ionic radius $r_{\mathrm{Na}}=0.097 \mathrm{~nm}$.

${ }^{\mathrm{i}}$ Corrected from dihydrated disodium salt with $v_{\mathrm{H}_{2} \mathrm{O}}=0.030 \mathrm{~nm}^{3}$ and ionic radius $r_{\mathrm{Na}}=0.097 \mathrm{~nm}$.
(12:0) ${ }_{2} \mathrm{PEMe}_{2},(16: 0 / 0: 0) \mathrm{PEMe}_{2},(16: 0 / 0: 0) \mathrm{PC},(0-16: 0 / 0: 0) \mathrm{PC}$ and (O-18:0/0-1:0)PC have head groups that interdigitate between opposing layers. All chains of the lipids in Table 2 are straight and saturated. The volume of the polar group, $v_{\text {pol }}$, in the crystal can be estimated by subtracting the total volume of the methylene and methyl groups in the chains, using the values $v_{\mathrm{CH}_{2}}=$ $0.0237 \mathrm{~nm}^{3}$ and $v_{\mathrm{CH}_{3}}=0.0395 \mathrm{~nm}^{3}$ that were obtained from crystalline alkanes (Table 1). This definition of the polar group is indicated schematically in Fig. 3; it includes the carbonyls of the acyl chains. The values obtained for $v_{\text {pol }}$ are listed in Table 2 . They follow the relative sizes expected for the various lipid species: $\mathrm{PC}>\mathrm{PEMe}_{2}>\mathrm{PEMe}>\mathrm{PE}>\mathrm{PA}>\mathrm{DG}$.

Within a given species, only $(12: 0)_{2} \mathrm{PA}$ and $(14: 0)_{2} \mathrm{PA}$ with $v_{\text {pol }}=0.223 \pm 0.006 \mathrm{~nm}^{3}$, and (12:0 $)_{2} \mathrm{DG}$ and (16:0 $)_{2} \mathrm{DG}$ with $v_{\text {pol }}=$ $0.154 \pm 0.003 \mathrm{~nm}^{3}$, should be directly comparable, and are so. All other crystalline phospholipids of a single head-group type differ in the chain linkage, in the presence of the second chain, and/or have propanediol instead of a glycerol backbone. The propanediol (i.e., 2-deoxy) lipids clearly have smaller polar volumes than do the diacyl species, although this is not unambiguously the case for lysolipids in which one $\mathrm{H}$-atom replaces a carbonyl, nor for ether linkages which lack one carbonyl. If differences between the latter are ignored, mean values of $v_{\text {pol }}=0.376 \pm 0.011,0.268 \pm 0.006$, $0.335 \pm 0.011,0.217 \pm 0.009$ and $0.162 \pm 0.007 \mathrm{~nm}^{3}$ are obtained for PC, PE, PEMe $\mathrm{P}_{2}$, PA and deoxylysoPA polar groups, respectively. For comparison, the molecular volumes of crystalline glycerylphosphorylcholine (GPC) and glycerylphosphorylethanolamine (GPE) are: 0.316 and $0.227 \mathrm{~nm}^{3}$, respectively (Abrahamsson and Pascher, 1966; DeTitta and Craven, 1973). For crystalline glycerol-2phosphate (analogous to 14:0/PA/0:0), the molecular volume after correction for water of hydration and sodium ions is $0.126 \mathrm{~nm}^{3}$ (Ul-haque and Caughlan, 1966). The polar groups in phospholipid crystals have comparable but larger volumes and therefore are less tightly packed than are the isolated headgroup moieties, GPC and GPE.

\subsection{Polar group $\left(v_{\text {pol }}\right)$ and terminal methyl $\left(v_{\mathrm{CH}_{3}}\right)$ volumes}

Since the pioneering work of Reiss-Husson and Luzzati (1964), and see also Tardieu et al. (1973) and Nagle and Wilkinson (1978), it has been customary to estimate the volume of the polar group in lipid membranes by assuming that the volume of a terminal methyl group is twice that of a methylene group, as in liquid hydrocarbons. The latter are isotropic phases, whereas membranes are ordered liquid-crystalline phases (see e.g., Cevc and Marsh, 1987). Therefore, it is uncertain to what extent this approximation holds true. Note, in particular, that both the temperature expansion coefficient (Koenig and Gawrisch, 2005) and compressibility (Wiener and White, 1992) of the terminal methyl groups are much greater than those of the methylenes, which is not compatible with a fixed ratio between the two. Alternatively, an estimate for the polar-group volume is afforded by the crystal volumes of GPC and GPE, adjusted by the van der Waals volume of the carbonyl substitution for the $\mathrm{H}$-atoms of the glycerol hydroxyls (Bondi, 1964). Combined with measured values of $v_{\text {end }}$, this value for $v_{\text {pol }}$ then yields an estimate for the ratio of methyl and methylene volumes, $v_{\mathrm{CH}_{3}} / v_{\mathrm{CH}_{2}}$.

Table 3 gives the results of such calculations for the various phosphatidylcholines and for phosphatidylethanolamines. First are given the volumes of the polar group, $v_{\text {pol }}$, deduced with a fixed value of the methyl to methylene volume ratio. A value of $v_{\mathrm{CH}_{3}} / v_{\mathrm{CH}_{2}}=2$ appropriate to fluid alkanes is assumed for the fluid $\mathrm{L}_{\alpha}$ phases, and a value of $v_{\mathrm{CH}_{3}} / v_{\mathrm{CH}_{2}}=1.7$ appropriate to orthorhombic crystalline alkanes for the $\mathrm{L}_{\beta}$ gel phase (see Table 1 ). For the unsaturated and isoacyl PCs, allowance must be made for the contribution of the $\mathrm{CH}$ methine groups and branched methyl groups, respectively, to $v_{\text {end }}$. This is done by using the values 

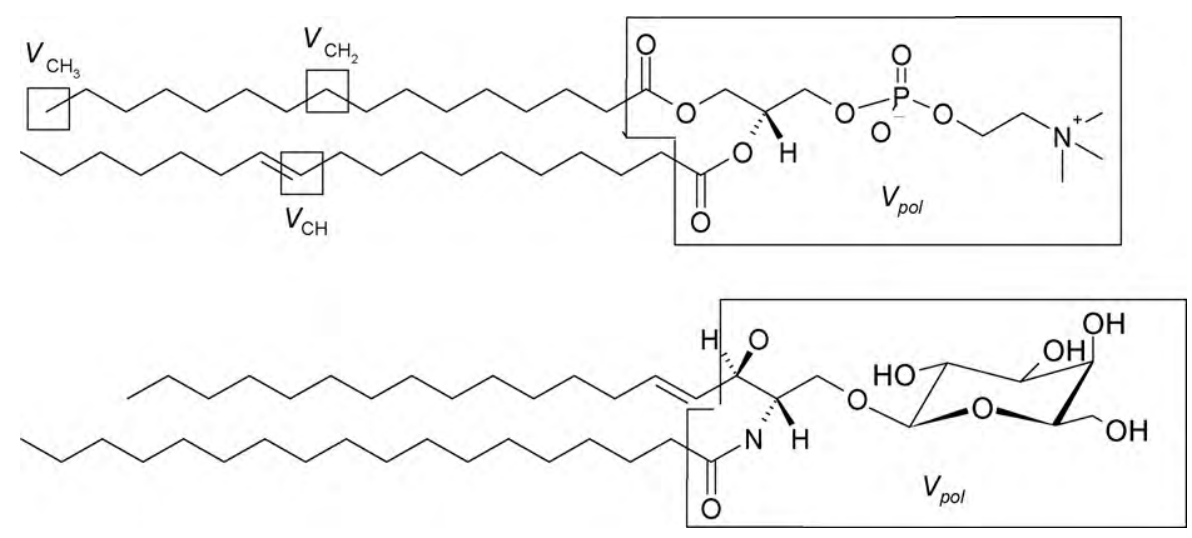

Fig. 3. Definition of the polar group in glycerolipids (top) and sphingolipids (bottom).

Table 3

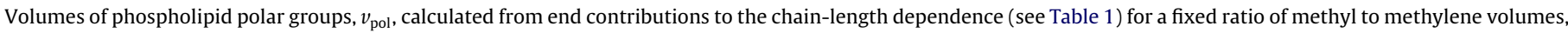
$v_{\mathrm{CH}_{3}} / v_{\mathrm{CH}_{2}}$, and vice-versa.

\begin{tabular}{|c|c|c|c|c|c|c|c|}
\hline Lipid & Phase & $T\left({ }^{\circ} \mathrm{C}\right)$ & $v_{\mathrm{CH}_{3}} / v_{\mathrm{CH}_{2}}{ }^{\mathrm{a}}$ & $v_{\mathrm{pol}}\left(\mathrm{nm}^{3}\right)$ & $v_{\mathrm{pol}}\left(\mathrm{nm}^{3}\right)^{\mathrm{a}}$ & $v_{\mathrm{CH}_{3}} / v_{\mathrm{CH}_{2}}$ & Ref. $^{b}$ \\
\hline$(n: 0)_{2} \mathrm{PC}$ & $\mathrm{L}_{\alpha}$ & 70 & 2 & 0.338 & 0.340 & 1.97 & 1 \\
\hline$(n: 1)_{2} \mathrm{PC}^{\mathrm{c}}$ & $\mathrm{L}_{\alpha}$ & 25 & 2 & 0.329 & 0.340 & 1.78 & 2 \\
\hline$\left(n: 0_{i}\right)_{2} P C^{d}$ & $\mathrm{~L}_{\alpha}$ & 40 & 2 & 0.332 & 0.340 & 1.88 & 3 \\
\hline \multirow[t]{2}{*}{$(n: 0)_{2} \mathrm{PE}$} & $\mathrm{L}_{\alpha}$ & 70 & 2 & 0.269 & 0.251 & 2.32 & 4 \\
\hline & $\mathrm{L}_{\beta}$ & 25 & 1.7 & 0.251 & 0.251 & 1.70 & 4,5 \\
\hline
\end{tabular}

a Maintained fixed.

b References: 1. Schmidt and Knoll, 1985; 2. Uhríková et al., 2007; 3. Yang et al., 1986; 4. Koynova and Hinz, $1990 ; 5$. Seddon et al., 1984.

${ }^{\mathrm{c} C a l c u l a t e d}$ with $v_{\mathrm{CH}}=0.021 \mathrm{~nm}^{3}$.

${ }^{\mathrm{d}}$ Calculated with $v_{\mathrm{iMe}}=0.031 \mathrm{~nm}^{3}$ for the methyl branch.

obtained as described above and noted in the footnotes to Table 3. Consistent values for the volume of the PC polar group in fluid membranes $v_{\mathrm{PC}}=0.336 \mathrm{~nm}^{3}$ must be obtained in this way, the differences corresponding only to the slight temperature dependence. This value is somewhat smaller than that deduced from phosphatidylcholine crystals $\left(v_{\mathrm{PC}}=0.376 \pm 0.011 \mathrm{~nm}^{3}\right)$, but similar to the volume of $v_{\mathrm{PC}}=0.340 \mathrm{~nm}^{3}$ in crystals of the GPC headgroup alone, after adjustment for the carbonyl contribution.

For phosphatidylethanolamine, on the other hand, the volume of the PE polar group in fluid membranes, $v_{\mathrm{PE}}=0.269 \mathrm{~nm}^{3}$ (Table 3 ) is very similar to that in the crystal $\left(v_{\mathrm{PE}}=0.268 \pm 0.006 \mathrm{~nm}^{3}\right.$, which is not much larger than the carbonyl-adjusted volume in crystals of the GPE headgroup alone $\left(v_{\mathrm{PE}}=0.251 \mathrm{~nm}^{3}\right)$. In the $\mathrm{L}_{\beta}$ gel phase, the PE polar-group volume is only slightly smaller than in the fluid $\mathrm{L}_{\alpha}$ phase and is very close to the carbonyl-adjusted volume in GPE crystals. The accordance between polar-group volumes in fluid phospholipid membranes and those in crystals for PE, but not for PC, correlates with the smaller, less hydrated, hydrogen-bonded head groups in the former case (Cevc and Marsh, 1985), which results in a packing that is more similar to that in the crystal. In PC membranes, on the other hand, the head groups are extensively hydrated, which allows more efficient packing than is possible in crystals of the mono- or dihydrate (cf. Table 2).

The second pair of entries in Table 3 gives the estimates for the methyl/methylene volume ratio, which are based on the volume of the polar-group alone with carbonyl contributions added. For the fluid $\mathrm{L}_{\alpha}$ phases, these values of $v_{\mathrm{CH}_{3}} / v_{\mathrm{CH}_{2}}$ are comparable to those found for liquid $n$-alkanes (viz., 2.0 and 2.1 at 40 and $70^{\circ} \mathrm{C}$, respectively). For gel-phase PE, the value of $v_{\mathrm{CH}_{3}} / v_{\mathrm{CH}_{2}}$ is close to that for orthorhombic crystalline alkanes, but that for the fluid phase somewhat exceeds the ratio for liquid alkanes. Taken as a whole, these results suggest that a methyl/methylene ratio of $v_{\mathrm{CH}_{3}} / v_{\mathrm{CH}_{2}} \approx 2$ is reasonable for the fluid phase, as concluded by other authors (Nagle and Wiener, 1988; Wiener and White, 1992; Koenig and Gawrisch, 2005), and that a ratio somewhat less than two (i.e., approaching that of orthorhombic crystalline hydrocarbons) is more appropriate for the gel phase of phosphatidylethanolamines.

\section{5. $\omega$-cyclohexyl chain volumes $\left(v_{c y c}\right)$}

Molecular volumes have also been determined for three chain lengths $(n=13-15)$ of diacyl phosphatidylcholines with $\omega$ cyclohexyl chains (Blume et al., 1987). Here the terminal methyl group (not counted in $n$ ) is replaced by the cyclohexyl moiety. At $60{ }^{\circ} \mathrm{C}$ in the $\mathrm{L}_{\alpha}$ phase, the methylene volume is $v_{\mathrm{CH}_{2}} \approx 0.027 \pm$ $0.001 \mathrm{~nm}^{3}$, and the volume contribution of each cyclohexyl group is estimated to be $v_{\mathrm{cyc}}=0.150 \pm 0.014 \mathrm{~nm}^{3}$ by assuming a PC polar group volume of $v_{\mathrm{pol}}=0.340 \mathrm{~nm}^{3}$ (see above). For comparison, the molecular volume in liquid cyclohexane is $v_{\text {mol }}=0.180 \mathrm{~nm}^{3}$ at $20^{\circ} \mathrm{C}(\rho=0.7785 \mathrm{~g} / \mathrm{ml})$.

\section{Glycoglycerolipids}

\subsection{Chain-length dependence and $\mathrm{CH}_{2}$ volume}

Fig. 4 shows the chain-length dependence of the molecular volume of the 1,2-dialkyl-3- $\beta$-D-glucosyl-sn-glycerol glycolipids (abbreviated (O-n:0) $)_{2}$ Glc $\left.\beta D G\right)$ in the crystalline $\left(\mathrm{L}_{\mathrm{c}}\right)$, gel $\left(\mathrm{L}_{\beta}\right)$ and fluid $\left(\mathrm{L}_{\alpha}\right)$ lamellar membrane phases, and in the fluid inverted hexagonal phase $\left(\mathrm{H}_{\mathrm{II}}\right)$. A linear dependence on chain length at fixed temperature is found in each of the different phases. Table 4 gives the parameters of the linear regressions, $v_{\mathrm{CH}_{2}}$ and $v_{\text {end }}$, for the $(0-n: 0)_{2}$ Glc $\beta D G$ series shown in Fig. 4, and more limited data for the corresponding series of galactosyl diacylglycerols, (O$n: 0)_{2}$ Gal $\beta$ DG. The crystalline $\mathrm{L}_{\mathrm{c}}$ phases are characterised by a very low methylene group volume, $v_{\mathrm{CH}_{2}}=0.021 \pm 0.001 \mathrm{~nm}^{3}$, which is even lower than that registered in crystalline $n$-alkanes $\left(v_{\mathrm{CH}_{2}}=\right.$ $\left.0.024 \mathrm{~nm}^{3}\right)$. This could indicate a different chain packing mode in glycolipids from that in crystalline paraffins. The methylene group volume in the $\mathrm{L}_{\beta}$ gel phase of glycoglycerolipids is larger 
Table 4

Component volumes of molecular groups, obtained by linear regression to the chain-length dependence (Eq. (4)) for glycoglycerolipids in membranes (see Fig. 4 ) .

\begin{tabular}{|c|c|c|c|c|c|c|}
\hline \multirow[t]{2}{*}{ Lipid } & \multirow[t]{2}{*}{ Phase } & \multirow[t]{2}{*}{$T\left({ }^{\circ} \mathrm{C}\right)$} & \multicolumn{2}{|l|}{$v_{\mathrm{CH}_{2}}$} & \multicolumn{2}{|l|}{$v_{\text {end }}{ }^{\mathrm{b}}$} \\
\hline & & & $\left(\mathrm{nm}^{3}\right)$ & $(\mathrm{ml} / \mathrm{mol})$ & $\left(\mathrm{nm}^{3}\right)$ & $(\mathrm{ml} / \mathrm{mol})$ \\
\hline \multirow[t]{3}{*}{$(0-n: 0)_{2}$ Glc $\beta D G$} & $\mathrm{~L}_{\mathrm{c}}$ & 20 & $0.0214 \pm 0.0008$ & $12.9 \pm 0.5$ & $0.408 \pm 0.022$ & $245 \pm 13$ \\
\hline & $\mathrm{L}_{\beta}$ & 20 & $0.0226 \pm 0.0006$ & $13.6 \pm 0.3$ & $0.411 \pm 0.016$ & $248 \pm 9$ \\
\hline & $\mathrm{H}_{\mathrm{II}}$ & 80 & $0.0265 \pm 0.0007$ & $16.0 \pm 0.4$ & $0.414 \pm 0.022$ & $250 \pm 13$ \\
\hline \multirow[t]{2}{*}{$(\mathrm{O}-n: 0)_{2}$ Gal $\beta$ DG } & $\mathrm{L}_{\mathrm{c}}$ & $20,65^{c}$ & $0.0207 \pm 0.0013$ & $12.5 \pm 0.8$ & $0.452 \pm 0.032$ & $272 \pm 19$ \\
\hline & $\mathrm{H}_{\text {II }}$ & 80 & $0.0250 \pm 0.002$ & $15.1 \pm 1.3$ & $0.437 \pm 0.060$ & $263 \pm 36$ \\
\hline
\end{tabular}

a Densitometric data from Hinz et al. (1991).

b Total volume of all molecular groups other than the chain methylenes: $v_{\text {end }}=v_{\mathrm{pol}}+2 v_{\mathrm{CH}_{3}}$.

c Combines data for $n=12,14$ at $20^{\circ} \mathrm{C}$ with that for $n=16,18$ at $65^{\circ} \mathrm{C}$ (all in the crystalline state).

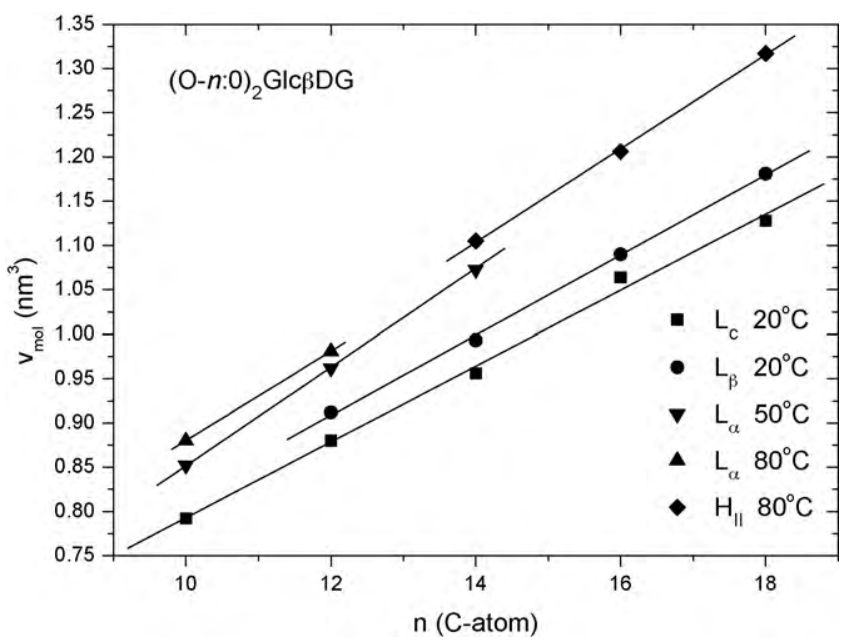

Fig. 4. Dependence of lipid molecular volume on alkyl chain length, $n$, for 1,2dialkyl-3- $\beta$-D-glucosyl-sn-glycerols, $(\mathrm{O}-n: 0)_{2} \mathrm{Glc} \beta D G$, in the $\mathrm{L}_{c}$ phase at $20^{\circ} \mathrm{C}$ (squares), in the $\mathrm{L}_{\beta}$ phase at $20^{\circ} \mathrm{C}$ (circles), in the $\mathrm{L}_{\alpha}$ phase at $50^{\circ} \mathrm{C}$ (downward triangles) and $80^{\circ} \mathrm{C}$ (upward triangles), and in the $\mathrm{H}_{\mathrm{II}}$ phase at $80^{\circ} \mathrm{C}$ (diamonds). Data from Hinz et al. (1991). Lines are linear regressions.

than that in the crystalline phase, but still remains relatively small $\left(v_{\mathrm{CH}_{2}}=0.023 \pm 0.001 \mathrm{~nm}^{3}\right)$. In the fluid $\mathrm{H}_{\mathrm{II}}$ phase, the methylene volume is larger: $v_{\mathrm{CH}_{2}} \approx 0.026 \pm 0.001 \mathrm{~nm}^{3}$, but somewhat lower than for phospholipids in the $\mathrm{L}_{\alpha}$ phase, especially the phosphatidylcholines. On the whole, the glycolipid chains appear to pack more densely than do those of the phospholipids, particularly in the more condensed phases. This can be attributed to lower hydration and hydrogen bonding between the sugar headgroups.

\subsection{Glycoglycerolipid polar group volumes}

Table 5 presents the results of calculations of the volumes of the polar groups in the $(0-n: 0)_{2}$ Glc $\beta D G$ and $(0-n: 0)_{2}$ Gal $\beta D G$ series. Values for the methyl to methylene volume ratio, $v_{\mathrm{CH}_{3}} / v_{\mathrm{CH}_{2}}$, are assumed as in Table 3 for the $\mathrm{L}_{\alpha}$ and $\mathrm{L}_{\beta}$ phases of phospholipids, together with $v_{\mathrm{CH}_{3}} / v_{\mathrm{CH}_{2}}=1.65$ (see crystalline alkane data in Table 1) for the $L_{c}$ phases of the glycolipids. Comparable volumes are obtained for both hexose head groups, but with slightly larger values for the galactosyl dialkylglycerols than for the glucosyl dialkylglycerols. The effective polar-group volumes in the gel phase are comparable to those in the fluid phase. Note that all lipids in these series are dialkyl glycerols with ether-linked chains and therefore $v_{\text {pol }}$ does not include the carbonyl groups that would be contributed by the chains of diacyl lipids.

Also included in Table 5 are data for a further monoglycosyl dialkylglycerol, $(0-n: 0)_{2}$ Man $\beta D G$, and for the diosyl and triaosyl diacylglycerols, (O-n:0) $)_{2}$ Mal $\beta D G$ and $(0-n: 0)_{2}$ Mtr $\beta D G$, which contain two and three hexose units, respectively, in the polar head group. Partial specific volumes are available for only one
Table 5

Volumes of glycoglycerolipid polar groups, $v_{\mathrm{pol}}$, in membranes calculated from end contributions (see Table 4 ) a $^{\mathrm{a}}$ for a fixed ratio of methyl to methylene volumes, $v_{\mathrm{CH}_{3}} / v_{\mathrm{CH}_{2}}$.

\begin{tabular}{|c|c|c|c|c|}
\hline Lipid & Phase & $T\left({ }^{\circ} \mathrm{C}\right)$ & $v_{\mathrm{CH}_{3}} / v_{\mathrm{CH}_{2}}{ }^{\mathrm{b}}$ & $v_{\mathrm{pol}}\left(\mathrm{nm}^{3}\right)$ \\
\hline \multirow[t]{3}{*}{$(\mathrm{O}-n: 0)_{2} \mathrm{Glc} \beta \mathrm{DG}$} & $\mathrm{L}_{\mathrm{c}}$ & 20 & 1.65 & 0.337 \\
\hline & $\mathrm{L}_{\beta}$ & 20 & 1.7 & 0.334 \\
\hline & $\mathrm{H}_{\mathrm{II}}$ & 80 & 2 & 0.308 \\
\hline \multirow[t]{2}{*}{$(0-n: 0)_{2}$ Gal $\beta D G$} & $\mathrm{~L}_{\mathrm{c}}$ & 20,65 & 1.65 & 0.384 \\
\hline & $\mathrm{H}_{\text {II }}$ & 80 & 2 & 0.337 \\
\hline \multirow[t]{2}{*}{$(\mathrm{O}-n: 0)_{2} \mathrm{Man} \beta \mathrm{DG}$} & $\mathrm{L}_{\beta}{ }^{\mathrm{c}}$ & 20 & 1.7 & 0.316 \\
\hline & $\mathrm{H}_{\text {II }}{ }^{\mathrm{d}}$ & 80 & 2 & 0.335 \\
\hline \multirow[t]{2}{*}{$(\mathrm{O}-n: 0)_{2} \mathrm{Mal} \beta \mathrm{DG}$} & $\mathrm{L}_{\beta}{ }^{\mathrm{c}}$ & 20 & 1.7 & 0.512 \\
\hline & $\mathrm{L}_{\alpha}^{\mathrm{d}}$ & 80 & 2 & 0.513 \\
\hline \multirow[t]{2}{*}{$(0-n: 0)_{2} \mathrm{Mtr} \beta D G$} & $\mathrm{~L}_{\beta}{ }^{\mathrm{c}}$ & 20 & 1.7 & 0.612 \\
\hline & $\mathrm{L}_{\alpha}^{\mathrm{d}}$ & 80 & 2 & 0.636 \\
\hline
\end{tabular}

a Densitometric data from Hinz et al. (1991).

b Maintained fixed.

c Calculated from $v_{\text {mol }}$ with $v_{\mathrm{CH}_{2}}=0.0226 \mathrm{~nm}^{3}$ from (O-n:0) $)_{2} \mathrm{Glc} \beta D G$.

d Calculated from $v_{\text {mol }}$ with $v_{\mathrm{CH}_{2}}=0.0258 \mathrm{~nm}^{3}$ from mean of $(0-n: 0)_{2} \mathrm{Glc} \beta D G$ and $(0-n: 0)_{2}$ Gal $\beta D G$.

or two chain lengths of these lipids. Therefore, values for the methylene group volume could not be determined from a chainlength dependence. Instead, the mean values of $v_{\mathrm{CH}_{2}}$ obtained from the $(\mathrm{O}-n: 0)_{2}$ Glc $\beta D G$ and $(0-n: 0)_{2}$ Gal $\beta D G$ series are assumed for the fluid phase of $(0-n: 0)_{2}$ Man $\beta D G,(0-n: 0)_{2}$ Mal $\beta D G$ and $(0-$ $n: 0)_{2} \mathrm{Mtr} \beta D G$, and the single value from the $(0-n: 0)_{2}$ Glc $\beta D G$ series is taken for the gel phase. The total contribution of the methylene and methyl groups is then subtracted from the molecular volume of the whole lipid to obtain $v_{\text {pol }}$. This method has often been applied previously to estimate the polar head group volume from the partial specific volume of a single lipid (Tardieu et al., 1973; Nagle and Wilkinson, 1978; Gulik et al., 1995). The values of $v_{\text {pol }}$ obtained for $(0-n: 0)_{2}$ Man $\beta D G$ are comparable to those for the other two monohexosyl diacylglycerols, $(0-n: 0)_{2}$ Glc $\beta D A G$ and $(0-n: 0)_{2}$ Gal $\beta D G$, and those obtained for the diosyl and triaosyl diacylglycerols are progressively larger. The increment in $v_{\text {pol }}$ between (O- $\left.n: 0\right)_{2}$ Man $\beta D G$ and (O- $\left.n: 0\right)_{2}$ Mal $\beta D G$ is $\Delta v_{\mathrm{pol}}=0.196$ and $0.178 \mathrm{~nm}^{3}$ in the gel and fluid phases, respectively. This compares well with the volume of a single hexose unit which is $\sim 0.192 \mathrm{~nm}^{3}$, as estimated from the density of glucose $\left(1.5620 \mathrm{~g} / \mathrm{cm}^{3}\right)$. On the other hand, the increment between $(\mathrm{O}-n: 0)_{2} \mathrm{Mtr} \beta \mathrm{DG}$ and $(\mathrm{O}-n: 0)_{2} \mathrm{Mal} \beta \mathrm{DG}$, corresponding to addition of a third hexose unit, is considerably smaller: $\Delta v_{\text {pol }} \sim 0.100$ and $0.123 \mathrm{~nm}^{3}$ in gel and fluid phases, respectively. This attenuating effect is seen in Fig. 5, in which the molecular volumes of $(\mathrm{O}$ $18: 0)_{2}$ glycosyl diacylglycerols with a common chain length are plotted against the number of hexose units in the polar head group, both for gel-phase membranes and for $\mathrm{L}_{\alpha}$ or $\mathrm{H}_{\text {II }}$ fluid phases. In the two cases, the volume increment between monoglycosyl $\left(n_{\text {glyc }}=1\right)$ and diosyl $\left(n_{\text {glyc }}=2\right)$ lipids is considerably larger than that 


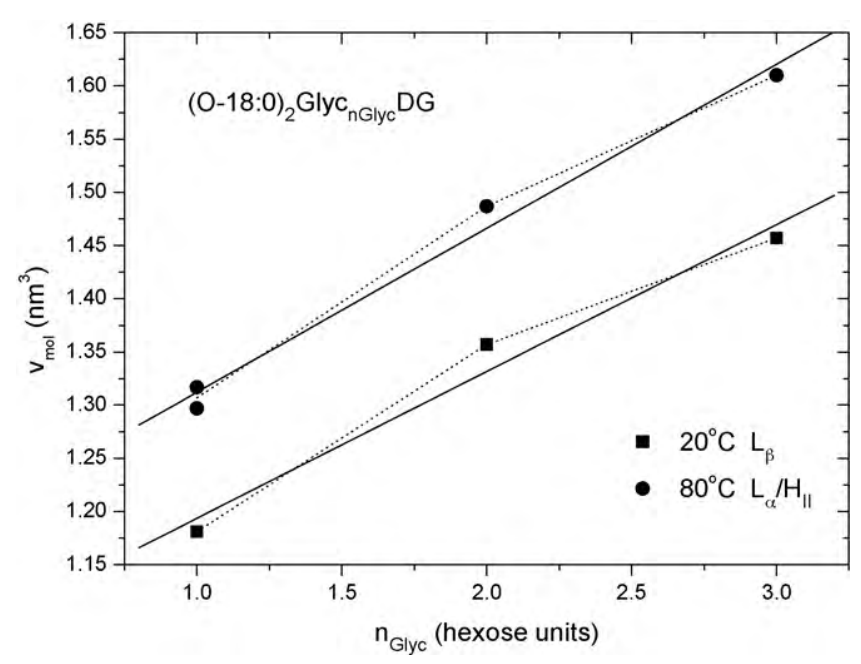

Fig. 5. Dependence of lipid molecular volume on number of glycosyl units, $n_{\text {Glyc }}$ in the lipid polar head group for 1,2-(0-18:0 $)_{2}$ monoglycosyl, $\left(n_{\mathrm{Glyc}}=1\right)$, diosyl $\left(n_{\text {Glyc }}=2\right)$, and triaosyl $\left(n_{\text {Glyc }}=3\right) s n-3$-glycerols in the $\mathrm{L}_{\beta}$ phase at $20^{\circ} \mathrm{C}$ (squares) and in the $\mathrm{L}_{\alpha}$ or $\mathrm{H}_{\text {II }}$ phase at $80^{\circ} \mathrm{C}$ (circles). Data from Hinz et al. (1991). Lines are linear regressions.

between triaosyl $\left(n_{\mathrm{glyc}}=3\right)$ and diosyl lipids. A linear regression to the combined data for the three lipid classes yields gradients of $0.138 \pm 0.021$ and $0.154 \pm 0.012 \mathrm{~nm}^{3} /$ hexose in gel and fluid phases, respectively.

\section{Glycosphingolipids}

Systematic chain-length dependences of the partial specific volume are not available for sphingolipids. Therefore, component polar-group volumes may only be deduced by assuming values for $v_{\mathrm{CH}_{2}}$ and $v_{\mathrm{CH}_{3}}$. This can be done most directly for the crystalline states, by using the values from crystalline $n$-alkanes as was done in Table 2 for phospholipids.

\subsection{Glycosphingolipid crystal volumes}

Table 6 gives the lipid molecular volumes in crystals of glycosphingolipids, ceramides and the sphingosine base. The contributions of any solvent molecules and/or counterions have been subtracted to yield the molecular volume, $v_{\text {mol }}$, of the sphingolipid. Correspondingly, the total volume of chain methylene and methyl groups has been subtracted from $v_{\text {mol }}$ to yield $v_{\text {pol }}$, the volume of the polar group, as was done in Table 2 for the phospholipid crystals. The polar group so-defined includes, in addition to the sugar group, also the carbonyl of the $\mathrm{N}$-acyl chain and all atoms of the sphingoid base up to and including the $\mathrm{OH}$-bearing $\mathrm{C}-3$ atom (see Fig. 3). For sphingosine (sphing-4-enine), this definition includes the $2 \mathrm{H}$-atom deficit, relative to $\mathrm{CH}_{2}$, that is contributed by the two $\mathrm{CH}$ groups of the 4-5 trans double bond, which lies immediately outside the polar-group region.

The polar group volumes of both cerebrosides in Table 6 contain an additional contribution from hydroxylation: of the $N$-acyl chain for Gal $\beta 1 \operatorname{Cer}(\mathrm{d} 18: 0 / 2(\mathrm{OH}) 18: 0)$ and of the sphingoid chain for Glc $\beta 1 \operatorname{Cer}(\mathrm{t} 18: 0 / 0: 0)$. Subtracting $v_{\text {pol }}$ for the ceramide $\operatorname{Cer}(\mathrm{t} 18: 0 / 24: 0)$ (which also includes an additional contribution from a single-OH substitution) from that of Gal $\beta 1 C e r(d 18: 0 / 2(\mathrm{OH}) 18: 0)$ yields a value of $v_{\mathrm{Gal}}=0.201 \mathrm{~nm}^{3}$ for the hexose unit. This value corresponds reasonably well with the hexose volume $v_{\mathrm{Glc}}=0.193 \mathrm{~nm}^{3}$ that is obtained directly for solid glucose (see above). Subtracting instead the value of $v_{\text {pol }}$ for the single-chain glucosyl phytosphingosine Glc $\beta 1 \operatorname{Cer}(\mathrm{t} 18: 0 / 0: 0)$ from that of Gal $\beta 1 \mathrm{Cer}(\mathrm{d} 18: 0 / 2(\mathrm{OH}) 18: 0)$ yields a difference of $0.046 \mathrm{~nm}^{3}$
Table 6

Molecular volumes in glycosphingolipid crystals.

\begin{tabular}{|c|c|c|c|}
\hline Lipid $^{\mathrm{a}}$ & $v_{\mathrm{mol}}\left(\mathrm{nm}^{3}\right)$ & $v_{\mathrm{pol}}\left(\mathrm{nm}^{3}\right)^{\mathrm{b}}$ & Ref. $^{c}$ \\
\hline Gal $\beta 1 \operatorname{Cer}(\mathrm{d} 18: 0 / 2(\mathrm{OH}) 18: 0)^{\mathrm{d}, \mathrm{e}}$ & $1.153 \pm 0.002$ & $0.364 \pm 0.002$ & 1 \\
\hline Glc $\beta 1 \operatorname{Cer}(\mathrm{t} 18: 0 / 0: 0)^{\mathrm{f}, \mathrm{g}}$ & $0.688 \pm 0.006$ & $0.318 \pm 0.005$ & 2 \\
\hline $\operatorname{Cer}(\mathrm{t} 18: 0 / 24: 0)^{\mathrm{g}}$ & $1.094 \pm 0.004$ & $0.163 \pm 0.004$ & 3 \\
\hline $\operatorname{Cer}\left(\mathrm{t} 18: 0 / 2,3(\mathrm{OH})_{2} 18: 0\right)^{\mathrm{e}, \mathrm{g}}$ & $0.9558 \pm 0.0008$ & $0.1672 \pm 0.0008$ & 4 \\
\hline $\operatorname{Cer}(\mathrm{d} 18: 1 / 0: 0)^{\mathrm{h}, \mathrm{i}}$ & $0.4808 \pm 0.0008$ & $0.1101 \pm 0.0008$ & 5 \\
\hline
\end{tabular}

a Gal $\beta 1 \mathrm{Cer}(\mathrm{d} 18: 0 / 2(\mathrm{OH}) 18: 0), 1-\beta$-D-galactosyl- $N$-(2-D-hydroxyoctadecanoyl)sphinganine; Glc $\beta 1 \mathrm{Cer}(\mathrm{t} 18: 0 / 0: 0)$, 1- $\beta$-D-glucosyl-4-hydroxysphinganine; Cer(t18:0/24:0), $N$-tetracosanoyl-4D-hydroxy-sphinganine ( $N$-tetracosanoylphytosphingosine); $\quad \operatorname{Cer}(\mathrm{t} 18: 0 / 2(\mathrm{OH}) 18: 0), \quad N$-(2D,3D-dihydroxyoctadecanoyl)4D-hydroxy-sphinganine ( $\mathrm{N}$-(2,3-dihydroxystearoyl)phytosphingosine); Cer(d18:1/0:0), sphing-4-enine (sphingosine). Note: d18:1 $\equiv$ sphing-4-enine (sphingosine); d18:0 $\equiv$ sphinganine (dihydrosphingosine); t18:0 $\equiv 4 \mathrm{D}-$ hydroxysphinganine (phytosphingosine).

b Includes C1-C3 and substituents of the sphingoid, and carbonyl of the amidelinked fatty acid.

c References: 1. Pascher and Sundell, 1977; 2. Abrahamsson et al., 1977; 3. Dahlen and Pascher, 1972; 4. Pascher and Sundell, 1992; 5. Abrahamsson et al., 1972.

d Corrected from ethanol solvate $(1 / 2 \mathrm{EtOH})$ with $v_{\mathrm{EtOH}} / 2=0.037 \mathrm{~nm}^{3}$ (Jönsson, 1976).

e $v_{\text {pol }}$ includes contribution of the $\mathrm{O}$-atom from the $(\mathrm{OH})$ substitution at $\mathrm{C}-2$ in the $\mathrm{N}$-acyl chain, which is otherwise counted as an unsubstituted $\mathrm{CH}_{2}$ group.

f Corrected from hydrochloride monohydrate with $v_{\mathrm{H}_{2} \mathrm{O}}=0.030 \mathrm{~nm}^{3}$ and ionic radius $r_{\mathrm{Cl}}=0.181 \mathrm{~nm}$.

$\mathrm{g} v_{\text {pol }}$ includes contribution of the O-atom from the $(\mathrm{OH})$ substitution at $\mathrm{C}-4$ in the (t18:0) sphingoid (phytosphingosine) chain, which is otherwise counted as an unsubstituted $\mathrm{CH}_{2}$ group.

$\mathrm{h}$ Corrected from hydrochloride with ionic radius $r_{\mathrm{Cl}}=0.181 \mathrm{~nm}$.

i $v_{\text {pol }}$ includes volume deficit, relative to $v_{\mathrm{CH}_{2}}$, of the two $\mathrm{CH}$ groups of the (d18:1) sphingosine.

which corresponds to the missing carbonyl in the single-chain derivative. Molecular dynamics simulations have suggested a contribution of $v_{\mathrm{C}=\mathrm{O}}=0.039 \pm 0.001 \mathrm{~nm}^{3}$ from each chain carbonyl in fluid phosphatidylcholine bilayers (Armen et al., 1998). The carbonyl volume in crystals might be expected to be smaller than this.

Subtracting the value of $v_{\text {pol }}$ for Cer(t18:0/24:0) from the cerebroside values, as above, but then adding back that for sphingosine Cer(d18:1/0:0), produces polar-group volumes appropriate to cerebrosides with sphingosine chains and no additional hydroxylation. These corrected values are $v_{\text {pol }}=0.311$ and $0.265 \mathrm{~nm}^{3}$ for the notional Gal $\beta 1 \operatorname{Cer}(\mathrm{d} 18: 1 / 0: 0)$ and $\operatorname{Glc} \beta 1 \operatorname{Cer}(\mathrm{d} 18: 1 / 0: 0)$ cerebrosides, respectively.

\subsection{Glycosphingolipid polar group volumes}

Considering now hydrated glycosphingolipids, the molecular volumes deduced from the partial specific volumes of the lipids dispersed in water are given in Table 7 . The accuracy of these determinations is limited by the fact that all lipids are derived from natural sources and have heterogeneous chain composition. The molecular volumes are deduced from Eq. (2) by assuming that the chains of the predominant species correspond to $\operatorname{Cer}(\mathrm{d} 18: 1 / 18: 0)$. The volumes of the polar groups are also deduced with this same assumption, which is therefore to some extent self-correcting. Volumes for chain methylene groups are, by default, taken to be those in fluid glycosyl diacylglycerols (see Table 4) and the approximation $v_{\mathrm{CH}_{3}} / v_{\mathrm{CH}_{2}} \approx 2$ is also used. The volume for a $\mathrm{CH}$ group is taken as that deduced above for phosphatidylcholines $\left(v_{\mathrm{CH}}=0.021 \mathrm{~nm}^{3}\right)$. The volume deduced for the polar group of the monoglycosyl sphingolipid GalCer is somewhat smaller than that found for fluid monoglycosyl glycoglycerolipids (see Table 5) and that calculated above for crystalline Gal $\beta 1 \mathrm{Cer}(\mathrm{d} 18: 1 / 0: 0)$ from the data in Table 6. It is, however, consistent with the relatively small increment in volume on increasing the number of hexose units in the sphingolipid head group. 
Table 7

Volumes of glycosphingolipid polar groups, $v_{\text {pol }}$, in membranes or micelles calculated from molecular volumes at $20^{\circ} \mathrm{C}$, assuming a Cer(d18:1/18:0) ceramide portion ${ }^{\mathrm{a}}$.

\begin{tabular}{llll}
\hline Lipid $^{\mathrm{b}}$ & $v_{\text {mol }}\left(\mathrm{nm}^{3}\right)$ & $v_{\text {pol }}\left(\mathrm{nm}^{3}\right)$ & Ref. $^{\mathrm{c}}$ \\
\hline GalCer & 1.122 & 0.257 & 1 \\
LacCer & 1.311 & 0.446 & 1 \\
$\mathrm{~Gb}_{3} \mathrm{Cer}$ & 1.52 & 0.655 & 1 \\
$\mathrm{Gg}_{3} \mathrm{Cer}$ & 1.527 & 0.662 & 1 \\
$\mathrm{Gg}$ Cer & 1.6971 & 0.8325 & 1 \\
$\mathrm{GM} 4$ & 1.462 & 0.597 & 1 \\
$\mathrm{GM} 3$ & 1.638 & 0.773 & 1 \\
$\mathrm{GM} 2$ & 1.876 & 1.011 & 1 \\
$\mathrm{GM} 1$ & 2.065 & 1.200 & 1 \\
& 2.0487 & 1.1841 & 2 \\
$\mathrm{GD} 3$ & 2.054 & 1.189 & 1 \\
$\mathrm{GD} 1 \mathrm{a}$ & 2.378 & 1.513 & 1 \\
& 2.3395 & 1.4749 & 2 \\
GD1b & 2.362 & 1.497 & 1 \\
GT1b & 2.659 & 1.794 & 1 \\
& 2.6307 & 1.7661 & 2
\end{tabular}

a Lipids are from natural sources. Predominant ceramide species is assumed to be Cer(d18:1/18:0), where d18:1 $\equiv$ sphing-4-enine (sphingosine). Hydrocarbon volumes in ceramide chains are taken as: $v_{\mathrm{CH}_{2}}=0.0257 \mathrm{~nm}^{3} ; v_{\mathrm{CH}}=0.021 \mathrm{~nm}^{3}$ and $v_{\mathrm{CH}_{3}} / v_{\mathrm{CH}_{2}}=2$ (see Tables 4 and 1 ).

b Lac, Galß1-4Glc; Gb 3 , Gal $\alpha 1-4 G a l \beta 1-4 G l c ; G_{3}$, GalNAc $\beta 1-4 G a l \beta 1-4 G l c ;$ $\mathrm{Gg}_{4}$, Gal $\beta 1$-3GalNAc $\beta 1$-4Gal $\beta 1$-4Glc; GM4, I ${ }^{3}$ NeuAc-Gal-Cer; GM3, II ${ }^{3}$ NeuAc-LacCer; GM2, II ${ }^{3} \mathrm{NeuAc}-\mathrm{Gg}_{3}-\mathrm{Cer}$; GM1, II ${ }^{3} \mathrm{NeuAc}-\mathrm{Gg}_{4}-\mathrm{Cer}$; GD3, II ${ }^{3} \mathrm{NeuAc}{ }_{2}$-Lac-Cer;

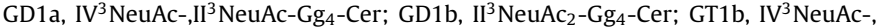
$\mathrm{II}^{3} \mathrm{NeuAc}_{2}-\mathrm{Gg}_{4}$-Cer.

c References: 1. Ulrich-Bott and Wiegandt, 1984; 2. Corti et al., 1991.

Fig. 6 shows the dependence of molecular volume on head group size for cerebrosides and asialogangliosides. The linear gradient is $0.195 \pm 0.009 \mathrm{~nm}^{3}$ per hexose unit, which is similar to the larger of the two values obtained for glycosyl diacylglycerols (cf. Fig. 4). As seen from Fig. 6, essentially the same gradient $\left(0.201 \pm 0.006 \mathrm{~nm}^{3}\right.$ per hexose) is also obtained with increasing headgroup size of the monosialogangliosides from GM4 to GM1. On the other hand, a steeper gradient is found for the dependence on the number of sialic acid residues in the head groups of gangliosides analogous to GM1. Molecular volumes for the series from asialoGM1

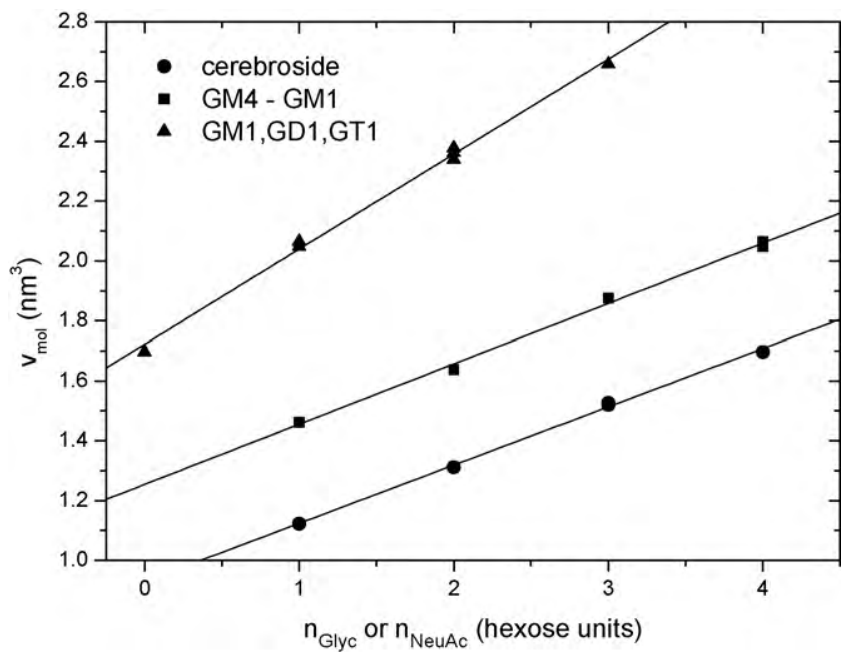

Fig. 6. Dependence of lipid molecular volume on number of glycosyl or $N$ acetylneuraminic acid units, $n_{\mathrm{Glyc}}$ or $n_{\mathrm{NeuAc}}$, in the lipid polar head group of glycosphingolipids for aqueous dispersions at $20^{\circ} \mathrm{C}$. Cerebrosides and asialogangliosides (circles); monosialogangliosides GM4 to GM1 (squares); polysialogangliosides asialoGM1, GM1, GD1 and GT1 (triangles). Data from Ulrich-Bott and Wiegandt (1984). Lines are linear regressions.
$\left(\mathrm{Gg}_{4} \mathrm{Cer}\right)$ to GT1b are shown in Fig. 6, from which a linear gradient of $0.301 \pm 0.009 \mathrm{~nm}^{3}$ per NeuAc unit is obtained for the volume of a sialic acid residue in the fluid micellar state.

\section{Conclusion}

Examining the chain-length dependence of lipid volumes in membranes gives rise to a consistent description in terms of component molecular groups, without recourse to diffraction results on bilayers. Originally, component values for the fluid $\mathrm{L}_{\alpha}$ phase were taken from liquid alkanes (Reiss-Husson and Luzzati, 1964): $v_{\mathrm{CH}_{2}}=$ $0.0270 \mathrm{~nm}^{3}, v_{\mathrm{CH}_{3}}=0.0540 \mathrm{~nm}^{3}, v_{\mathrm{CH}}=0.0205 \mathrm{~nm}^{3}$, together with the partial specific volume of egg phosphatidylcholine to estimate: $v_{\mathrm{pol}}=0.0360 \mathrm{~nm}^{3}$ for the PC polar group at $25^{\circ} \mathrm{C}$ (Tardieu et al., 1973). These values are reasonably close to those obtained here from densitometric measurements on PC bilayers alone (see Tables 1 and 3). The value of $v_{\text {pol }}$ for PC in Table 3 is somewhat lower than the above value, and also than early estimates from $\mathrm{X}$-ray diffraction (quoted in Nagle and Tristram-Nagle, 2000). However, more recent X-ray analyses have produced values that are in rather good accord with the present work, both for PC and PE (see Appendix, Table A.1). For instance, the latest high-resolution refinement yields a value of $v_{\text {pol }}=0.331 \mathrm{~nm}^{3}$ for the $\mathrm{L}_{\beta^{\prime}}$ phase of $(14: 0)_{2} \mathrm{PC}$ at $10^{\circ} \mathrm{C}$ (Tristram-Nagle et al., 2002). This value of $v_{\mathrm{pol}}$ has then been assumed in subsequent refinements for fluid-phase PC bilayers (Kucerka et al., 2005a,b; 2006).

Volumetric data for the $\mathrm{L}_{\beta}$ gel phase of phosphatidylethanolamine have been deduced previously from a combination of X-ray diffraction and density measurements on (12:0) $)_{2} \mathrm{PE}$ (see Table A.1). Values of $v_{\mathrm{CH}_{2}}=0.0260 \mathrm{~nm}^{3}$ and $v_{\text {pol }}=0.252 \mathrm{~nm}^{3}$ were obtained at $20^{\circ} \mathrm{C}$ (Nagle and Wiener, 1988), which are in good agreement with the present results from the chain-length dependence of phosphatidylethanolamine volumes (see Tables 1 and 3). The methyl group volume assumed $\left(v_{\mathrm{CH}_{3}} / v_{\mathrm{CH}_{2}}=1.75\right)$ is rather similar to that deduced here from data on crystalline alkanes. For the $\mathrm{L}_{\alpha}$ phase of $(12: 0)_{2} \mathrm{PE}$, the gel-phase value of $v_{\text {pol }}$ was assumed, together with $v_{\mathrm{CH}_{3}} / v_{\mathrm{CH}_{2}}=2$ from liquid $n$-alkanes. The methylene group volume was then estimated as $v_{\mathrm{CH}_{2}}=0.0273 \mathrm{~nm}^{3}$ at $35^{\circ} \mathrm{C}$ (Nagle and Wiener, 1988), which is reasonably close to the value found here.

In view of this measure of agreement, it seems reasonable to use the values established here for the chain volumes in phospholipid bilayers to estimate polar-group volumes for phospholipids for which volumetric data are available only for a single chain length. This approach has been used already for certain of the glycoglycerolipids, in Table 5. Estimates for the polar-group volumes of dialkyl phosphatidylcholines and phosphatidylethanolamines, of diacyl phosphatidylglycerol and phosphatidic acids, and of sphingomyelin, that are obtained in this way are given in Table 8. Of these, only $v_{\text {pol }}$ for dialkyl phosphatidylcholines has been obtained by other means, and the present value for the fluid phase is found to lie within the range estimated from X-ray methods (see Table A.1). This, therefore, gives some confidence in the values for other lipids reported in Table 8, and correspondingly for the diosyl and triaosyl glycerolipids in Table 5. Finally, it should be noted that the same method is also used to obtain estimates of the polar-group volumes of glycosphingolipids (for which volumetric data are much sparser) in Table 7.

\section{Acknowledgement}

I thank Frau Birgit Freyberg for EPR measurements and Frau Brigitta Angerstein for spin-label synthesis. 
Table 8

Volume of phospholipid polar groups, $v_{\text {pol }}$, in hydrated bilayer membranes, deduced from measurements of molecular volume, $v_{\text {mol }}$, for a single lipid chain length. ${ }^{\text {a }}$.

\begin{tabular}{|c|c|c|c|c|c|c|c|}
\hline Lipid & Phase & $T\left({ }^{\circ} \mathrm{C}\right)$ & $v_{\mathrm{mol}}\left(\mathrm{nm}^{3}\right)$ & $v_{\mathrm{CH}_{2}}\left(\mathrm{~nm}^{3}\right)^{\mathrm{b}}$ & $v_{\mathrm{CH}_{3}} / v_{\mathrm{CH}_{2}}$ & $v_{\mathrm{pol}}\left(\mathrm{nm}^{3}\right)$ & Ref. $^{c}$ \\
\hline \multirow[t]{2}{*}{$(\mathrm{O}-16: 0)_{2} \mathrm{PC}$} & $\mathrm{L}_{\beta}{ }^{\mathrm{i}}$ & 20 & 1.124 & 0.0241 & 1.7 & 0.319 & 1 \\
\hline & $\mathrm{L}_{\alpha}$ & 45 & 1.219 & 0.0275 & 2 & 0.284 & 1 \\
\hline \multirow[t]{4}{*}{$(0-12: 0)_{2} \mathrm{PE}$} & $\mathrm{L}_{\mathrm{c}}$ & 25 & 0.837 & 0.0241 & 1.65 & 0.227 & 2 \\
\hline & $\mathrm{L}_{\beta}$ & 24 & 0.868 & 0.0253 & 1.7 & 0.225 & 2 \\
\hline & $\mathrm{L}_{\alpha}$ & 59 & 0.914 & 0.0266 & 2 & 0.222 & 2 \\
\hline & $\mathrm{H}_{\mathrm{II}}$ & 135 & 0.983 & 0.0286 & 2 & 0.239 & 2 \\
\hline \multirow[t]{3}{*}{$(16: 0)_{2} \mathrm{PG}$} & $\mathrm{L}_{\beta^{\prime}}$ & 25 & 1.098 & 0.0253 & 1.7 & 0.304 & 3 \\
\hline & $\mathrm{P}_{\beta^{\prime}}$ & 37 & 1.136 & 0.0260 & 1.7 & 0.320 & 4 \\
\hline & $\mathrm{L}_{\alpha}$ & 45 & 1.178 & 0.0275 & 2 & 0.298 & 3 \\
\hline \multirow[t]{2}{*}{$(14: 0)_{2} \mathrm{PA}$} & $\mathrm{L}_{\beta}$ & 25 & 0.943 & 0.0253 & 1.7 & 0.250 & 5 \\
\hline & $\mathrm{L}_{\alpha}$ & 50 & 1.004 & 0.0269 & 2 & 0.250 & 5 \\
\hline EYSM $^{\mathrm{d}}$ & $\mathrm{L}_{\beta}$ & 30 & 1.160 & 0.0261 & 1.7 & 0.350 & 6 \\
\hline
\end{tabular}

a From additivity of volumes: $v_{\text {pol }}=v_{\mathrm{mol}}-n_{\mathrm{CH}_{2}} v_{\mathrm{CH}_{2}}-2 v_{\mathrm{CH}_{3}}$.

b From Table 1, with adjustments for temperature by using an expansion coefficient: $\alpha_{\mathrm{V}}=0.001 \mathrm{~K}^{-1}$.

c References: 1. Laggner et al., 1987; 2. Seddon et al., 1984; 3. Pabst et al., 2008; 4. Wilkinson et al., 1987; 5. Schmidt and Knoll, 1985 ; 6. Epand and Epand, 1980.

d Sphingomyelin from hen egg yolk, assuming that the predominant molecular species is SM(d18:1/16:0).

\section{Appendix A. Group contributions from X-ray diffraction}

It is useful, for comparison purposes, to collect together determinations of molecular group volumes that are based on refinement of electron density profiles from X-ray diffraction and scattering studies of fully hydrated bilayer membranes. In the liquid crystallographic method developed by Nagle, Tristram-Nagle and co-workers (Nagle and Tristram-Nagle, 2000; Tristram-Nagle et al., 2002), the electron density profile is fitted with the polar and hydrocarbon group contributions. In this way, it is possible to determine the position of the Gibbs dividing surface between hydrocarbon and polar regions, and hence to define the lipid hydrocarbon thickness, $d_{\text {HC. }}$.

The area per chain, $A_{\mathrm{ch}}$, in the gel phase is obtained from the wide-angle X-ray reflections, which give the chain spacings. This is then used together with the hydrocarbon thickness, and chain tilt $\left(\theta_{\mathrm{t}}\right)$ determined with aligned samples, to yield the volume of the hydrocarbon layer: $v_{\mathrm{HC}}=2 d_{\mathrm{HC}} A_{\mathrm{ch}} / \cos \theta_{t}$ per lipid. The volume of the lipid polar group is then simply: $v_{\mathrm{pol}}=v_{\mathrm{mol}}-v_{\mathrm{HC}}$. The methylene volume in the gel phase is estimated as $v_{\mathrm{CH}_{2}}=A_{\mathrm{ch}} \times$ $0.127 \mathrm{~nm}^{3}$, where $0.127 \mathrm{~nm}$ is the length per $\mathrm{CH}_{2}$ group along the axis of an all-trans chain. Thence, the volume of the terminal methyl

Table A.1

Group volumes from X-ray diffraction and densitometry.

\begin{tabular}{|c|c|c|c|c|c|c|c|}
\hline Lipid & Phase & $T\left({ }^{\circ} \mathrm{C}\right)$ & $v_{\mathrm{mol}}\left(\mathrm{nm}^{3}\right)$ & $v_{\mathrm{CH}_{2}}\left(\mathrm{~nm}^{3}\right)$ & $v_{\mathrm{CH}_{3}} / v_{\mathrm{CH}_{2}}$ & $v_{\mathrm{pol}}\left(\mathrm{nm}^{3}\right)$ & Ref. $^{a}$ \\
\hline$(12: 0)_{2} \mathrm{PC}$ & $\mathrm{L}_{\alpha}$ & 30 & 0.991 & $0.0277^{b}$ & 1.9 & $0.331^{c}$ & 1 \\
\hline$(14: 0)_{2} \mathrm{PC}$ & $\begin{array}{l}\mathrm{L}_{\beta^{\prime}} \\
\mathrm{L}_{\alpha}\end{array}$ & $\begin{array}{l}10 \\
30\end{array}$ & 1.041 & $\begin{array}{l}0.0252^{\mathrm{b}} \\
0.0277^{\mathrm{b}}\end{array}$ & $\begin{array}{l}2.06 \\
1.9\end{array}$ & $\begin{array}{l}0.331^{\mathrm{d}} \\
0.331^{\mathrm{c}}\end{array}$ & $\begin{array}{l}2 \\
1\end{array}$ \\
\hline$(16: 0)_{2} \mathrm{PC}$ & $\begin{array}{l}\mathrm{L}_{\beta^{\prime}} \\
\mathrm{L}_{\alpha}\end{array}$ & $\begin{array}{l}24 \\
50\end{array}$ & $\begin{array}{l}1.148 \pm 0.002 \\
1.2285\end{array}$ & $\begin{array}{l}0.02591 \pm 0.00005^{b} \\
0.0280^{b}\end{array}$ & $\begin{array}{l}2.05 \pm 0.05 \\
2\end{array}$ & $\begin{array}{l}0.319 \pm 0.006^{d} \\
0.331^{c}\end{array}$ & $\begin{array}{l}3 \\
4\end{array}$ \\
\hline$(18: 1 \mathrm{c})_{2} \mathrm{PC}$ & $\begin{array}{l}\mathrm{L}_{\alpha} \\
\mathrm{L}_{\alpha}\end{array}$ & $\begin{array}{l}23 \\
30\end{array}$ & $\begin{array}{l}1.2956 \pm 0.0007 \\
1.303\end{array}$ & $\begin{array}{l}0.027 \pm 0.001^{\mathrm{e}} \\
0.0277^{\mathrm{b}, \mathrm{g}}\end{array}$ & $\begin{array}{l}2.12 \pm 0.13 \\
1.92\end{array}$ & $\begin{array}{l}0.333 \pm 0.028^{f} \\
0.333^{c}\end{array}$ & $\begin{array}{l}5 \\
6\end{array}$ \\
\hline $\begin{array}{l}(22: 1 \mathrm{c})_{2} \mathrm{PC} \\
(16: 0 / 18: 1 \mathrm{c}) \mathrm{PC} \\
(18: 0 / 18: 1 \mathrm{c}) \mathrm{PC}\end{array}$ & $\begin{array}{l}\mathrm{L}_{\alpha} \\
\mathrm{L}_{\alpha} \\
\mathrm{L}_{\alpha}\end{array}$ & $\begin{array}{l}30 \\
30 \\
30\end{array}$ & $\begin{array}{l}1.522 \\
1.256 \\
1.3113\end{array}$ & $\begin{array}{l}0.0276^{b, g} \\
0.0276^{\text {b,g }} \\
0.0276 \pm 0.0007^{b, g}\end{array}$ & $\begin{array}{l}1.94 \\
1.94 \\
1.9\end{array}$ & $\begin{array}{l}0.330^{c} \\
0.331^{c} \\
0.333^{c}\end{array}$ & $\begin{array}{l}6 \\
6 \\
7\end{array}$ \\
\hline$(\mathrm{O}-16: 0)_{2} \mathrm{PC}$ & $\begin{array}{l}\mathrm{L}_{\beta}{ }^{\mathrm{i}} \\
\mathrm{L}_{\alpha}\end{array}$ & $\begin{array}{l}20 \\
48\end{array}$ & $\begin{array}{l}1.126 \\
1.223\end{array}$ & $\begin{array}{l}0.0245 \\
0.0280^{\mathrm{i}}\end{array}$ & $\begin{array}{l}2 \\
2^{\mathrm{i}}\end{array}$ & $\begin{array}{l}0.291^{\mathrm{h}} \\
0.270^{\mathrm{h}}\end{array}$ & $\begin{array}{l}8 \\
8\end{array}$ \\
\hline$(12: 0)_{2} \mathrm{PE}$ & $\begin{array}{l}\mathrm{L}_{\beta} \\
\mathrm{L}_{\alpha}\end{array}$ & $\begin{array}{l}20 \\
35\end{array}$ & $\begin{array}{l}0.863 \\
0.907\end{array}$ & $\begin{array}{l}0.0260^{b} \\
0.0273^{b}\end{array}$ & $\begin{array}{l}1.75^{\mathrm{j}} \\
2.0^{\mathrm{e}}\end{array}$ & $\begin{array}{l}0.252^{d} \\
0.252^{c}\end{array}$ & $\begin{array}{l}9 ; 10 \\
9-11\end{array}$ \\
\hline $\begin{array}{l}(14: 0)_{2} \mathrm{PS} \\
(18: 1 \mathrm{c})_{2} \mathrm{PS}\end{array}$ & $\begin{array}{l}\mathrm{L}_{\beta} \\
\mathrm{L}_{\alpha}\end{array}$ & $\begin{array}{l}20 \\
30\end{array}$ & $\begin{array}{l}0.979^{\mathrm{k}} \\
1.228\end{array}$ & $\begin{array}{l}0.0259^{\mathrm{b}} \\
0.0280^{\mathrm{b}, \mathrm{g}}\end{array}$ & $\begin{array}{l}2.16 \\
2^{\mathrm{e}}\end{array}$ & $\begin{array}{l}0.244^{\mathrm{m}} \\
0.244^{\mathrm{n}}\end{array}$ & $\begin{array}{l}12 \\
12\end{array}$ \\
\hline
\end{tabular}

a References: 1. Kucerka et al., 2005a; 2. Tristram-Nagle et al., 2002; 3.Sun et al., 1994; 4. Kucerka et al., 2006; 5 . Wiener and White, $1992 ; 6$. Kucerka et al., $2005 b ; 7$. Greenwood et al., 2008; 8. Guler et al., 2009; 9. McIntosh and Simon, 1986; 10. Nagle and Wiener, 1988; 11. McIntosh, 1986; 12 . Petrache et al., 2004.

b From additivity of volumes: $v_{\mathrm{pol}}=v_{\mathrm{mol}}-n_{\mathrm{CH}_{2}} v_{\mathrm{CH}_{2}}-2 v_{\mathrm{CH}_{3}}$.

c Assumed equal to gel-phase value.

d From X-ray refinement of hydrocarbon thickness, $d_{\mathrm{HC}}$, and lipid cross-sectional area, $A_{1}: v_{\mathrm{pol}}=v_{\mathrm{mol}}-A_{\mathrm{l}} d_{\mathrm{HC}}$.

e Assumed from liquid $n$-alkanes.

${ }^{f}$ Volume of $\mathrm{CH}$ group in double bond estimated as $v_{\mathrm{CH}}=0.023 \mathrm{~nm}^{3}\left(v_{\mathrm{CH}} / v_{\mathrm{CH}_{2}}=0.85\right)$.

g A fixed ratio of $v_{\mathrm{CH}} / v_{\mathrm{CH}_{2}}=0.80$ is assumed for the double-bond $\mathrm{CH}$ groups.

h Corrected for two chain $\mathrm{CH}_{2}$ groups included in head group in Guler et al. (2009).

i Assumed equal to values for (16:0) 2 PC (Guler et al., 2009).

j Assumed fixed.

k Deduced from $v_{\text {pol }}$ (see Petrache et al., 2004).

$\mathrm{m}$ Assumed equal to (18:1c) $)_{2}$ PS fluid-phase value.

${ }^{n}$ Deduced from comparison with (18:1c) 2 PC (see Petrache et al., 2004). 
groups in the gel phase is determined by subtracting the $\mathrm{CH}_{2}$ contribution from $v_{\mathrm{HC}}$.

It is assumed that the volume occupied by the polar group in the fluid $\mathrm{L}_{\alpha}$ phase is the same as that determined in the gel phase. The hydrocarbon volume is then obtained by subtracting this from $v_{\text {mol }}$. The volume per $\mathrm{CH}_{2}$ group in the fluid phase is then calculated from $v_{\mathrm{HC}}$ by using the ratios $v_{\mathrm{CH}_{3}} / v_{\mathrm{CH}_{2}}=1.9-2$ and $v_{\mathrm{CH}} / v_{\mathrm{CH}_{2}}=0.80$ for the contribution of the terminal methyls and unsaturated carbons, respectively. In practice, greater precision is achieved by global fitting of the electron density profiles, with the number of constraints required depending on the resolution and amount of experimental data available (including in some cases neutron scattering) (Kucerka et al., 2008).

These values for gel and fluid phases are collected together in Table A.1. Interestingly, the $v_{\mathrm{CH}_{3}} / v_{\mathrm{CH}_{2}}$ ratios that are obtained for the gel phase by this method are close to 2 .

\section{References}

Abrahamsson, S., Dahlén, B., Pascher, I., 1977. Molecular arrangements in glycosphingolipids - crystal structure of glucosylphytosphingosine hydrochloride. Acta Cryst. Sect. B 33, 2008-2013.

Abrahamsson, S., Pascher, I., 1966. Crystal and molecular structure of L- $\alpha-$ glycerylphosphorylcholin. Acta Cryst. 21, 79-87.

Abrahamsson, S., Pascher, I., Larsson, K., Karlsson, K.-A., 1972. Molecular arrangements in glycosphingolipids. Chem. Phys. Lipids 8, 152-179.

Armen, R.S., Uitto, O.D., Feller, S.E., 1998. Phospholipid component volumes: Determination and application to bilayer structure calculations. Biophys. J. 75, 734-744.

Bartucci, R., Páli, T., Marsh, D., 1993. Lipid chain motion in an interdigitated gel phase: conventional and saturation transfer ESR of spin-labelled lipids in dipalmitoylphosphatidylcholine-glycerol dispersions. Biochemistry 32, 274-281.

Blume, A., Habel, K., Finke, A., Frey, T., 1987. DSC studies of phospholipids containing iso-branched and $\omega$-cyclohexane fatty acids. Thermochim. Acta 119, 53-58.

Bondi, A., 1964. Van der Waals volumes and radii. J. Phys. Chem. 68, 441-451.

Cevc, G., Marsh, D., 1985. Hydration of non-charged lipid bilayer membranes. Theory and experiments with phosphatidylethanolamines. Biophys. J. 47, 21-31.

Cevc, G., Marsh, D., 1987. Phospholipid Bilayers. Physical Principles and Models. Wiley-Interscience, New York.

Corti, M., Cantu, L., Salina, P., 1991. Aggregation properties of biological amphiphiles. Adv. Colloid Interf. Sci. 36, 153-171.

Crissman, J.M., Passaglia, E., Eby, R.K., Colson, J.P., 1970. Crystal data on n-eicosane $\left(\mathrm{C}_{20} \mathrm{H}_{42}\right)$. J. Appl. Cryst. 3, 194-195.

Dahlen, B., Pascher, I., 1972. Molecular arrangements in sphingolipids - crystal structure of $\mathrm{N}$-tetracosanoylphytosphingosine. Acta Cryst. Sect. B 28, 2396-2404.

DeTitta, G.T., Craven, B.M., 1973. L- $\alpha$-glycerylphosphorylethanolamine monohydrate. Acta Cryst. Sect. B 29, 1354-1357.

Dorset, D.L., Pangborn, W.A., 1988. Polymorphic forms of 1, 2-dipalmitoyl-snglycerol: a combined X-ray and electron diffraction study. Chem. Phys. Lipids $48,19-28$.

Elder, M., Hitchcock, P., Mason, R., Shipley, G.G., 1977. A refinement analysis of the crystallography of the phospholipid, 1,2-dilauroyl-DLphosphatidylethanolamine, and some remarks on lipid-lipid and lipid-protein interactions. Proc. R. Soc. London A 354, 157-170.

Epand, R.M., Epand, R.F., 1980. Studies of thermotropic phospholipid phase transitions using scanning densitometry. Chem. Phys. Lipids 27, 139-150.

Fourmé, R., Renaud, M., 1966. Etude de la structure cristalline du choloroforme à 185K. C. R. Acad. Sc. Paris 263, 69-72.

Greenwood, A.I., Pan, J., Mills, T.T., Nagle, J.F., Epand, R.M., Tristram-Nagle, S., 2008. CRAC motif peptide of the HIV-1 gp41 protein thins SOPC membranes and interacts with cholesterol. Biochim. Biophys. Acta 1778, 1120-1130.

Guler, S.D., Ghosh, D.D., Pan, J., Mathai, J.C., Zeidel, M.L., Nagle, J.F., Tristram-Nagle, S., 2009. Effects of ether vs. ester linkage on lipid bilayer structure and water permeability. Chem. Phys. Lipids 160, 33-44.

Gulik, A., Delacroix, H., Kirschner, G., Luzzati, V., 1995. Polymorphism of gangliosidewater systems: a new class of micellar cubic phases. Freeze-fracture electron microscopy and X-ray scattering studies. J. Phys. II France 5, 445-464.

Harlos, K., Eibl, H., Pascher, I., Sundell, S., 1984. Conformation and packing properties of phosphatidic acid - the crystal structure of monosodium dimyristoylphosphatidate. Chem. Phys. Lipids 34, 115-126.

Hauser, H., Pascher, I., Sundell, S., 1980. Conformation of phospholipids - crystal structure of a lysophosphatidylcholine analogue. J. Mol. Biol. 137, 249-264.

Hinz, H.-J., Kuttenreich, H.L., Meyer, R., Renner, M., Fründ, R., Koynova, R., Boyanov, A.I., Tenchov, B.G., 1991. Stereochemistry and size of sugar head groups determine structure and phase behavior of glycolipid membranes - densitometric, calorimetic, and X-ray studies. Biochemistry 30, 5125-5138.

Jönsson, P.G., 1976. Hydrogen-bond studies. 113. Crystal structure of ethanol at 87K. Acta Crystallogr. Sect. B 32, 232-235.
Koenig, B.W., Gawrisch, K., 2005. Specific volumes of unsaturated phosphatidylcholines in the liquid crystalline lamellar phase. Biochim. Biophys. Acta 1715 65-70.

Koynova, R., Hinz, H.-J., 1990. Metastable behavior of saturated phosphatidylethanolamines - a densitometric study. Chem. Phys. Lipids 54, 67-72.

Kucerka, N., Liu, Y., Chu, N., Petrache, H.I., Tristram-Nagle, S., Nagle, J.F., 2005a. Structure of fully hydrated fluid phase DMPC and DLPC lipid bilayers using X-ray scattering from oriented multilamellar arrays and from unilamellar vesicles. Biophys. J. 88, 2626-2637.

Kucerka, N., Nagle, J.F., Feller, S.E., Balgavy, P., 2004. Models to analyze small-angle neutron scattering from unilamellar lipid vesicles. Phys. Rev. E Stat. Nonlin. Soft Matter Phys. 69, 051903.

Kucerka, N., Nagle, J.F., Sachs, J.N., Feller, S.E., Pencer, J., Jackson, A., Katsaras, J., 2008. Lipid bilayer structure determined by the simultaneous analysis of neutron and X-ray scattering data. Biophys. J. 95, 2356-2367.

Kucerka, N., Tristram-Nagle, S., Nagle, J.F., 2005b. Structure of fully hydrated fluid phase lipid bilayers with monounsaturated chains. J. Membr. Biol. 208, 193-202.

Kucerka, N., Tristram-Nagle, S., Nagle, J.F., 2006. Closer look at structure of fully hydrated fluid phase DPPC bilayers. Biophys. J. 90, L83-L85.

Laggner, P., Lohner, K., Degovics, G., Müller, K., Schuster, A., 1987. Structure and thermodynamics of the dihexadecylphosphatidylcholine-water system. Chem. Phys. Lipids 44, 31-60.

Lange, A., Marsh, D., Wassmer, K.-H., Meier, P., Kothe, G., 1985. Electron spin resonance study of phospholipid membranes employing a comprehensive lineshape model. Biochemistry 24, 4383-4392.

Luzzati, V., 1968. X-ray diffraction studies of lipid-water systems. In: Chapman, D. (Ed.), Biological Membranes. Academic Press, London, pp. 71-123.

Marsh, D., 1990. Handbook of Lipid Bilayers. CRC Press, Boca Raton FL.

Marsh, D., 2009. Electron spin resonance in membrane research: protein-lipid interactions. Methods 46, 83-96.

Marsh, D., Páli, T., 2006. Lipid conformation in crystalline bilayers and in crystals of transmembrane proteins. Chem. Phys. Lipids 141, 48-65.

Marsh, D., Watts, A., 1982. Spin-labeling and lipid-protein interactions in membranes. In: Jost, P.C., Griffith, O.H. (Eds.), Lipid-Protein Interactions, Vol. 2. Wiley-Interscience, New York, pp. 53-126.

McIntosh, T.J., 1986. Correction. Biochemistry 25, 4874.

McIntosh, T.J., Simon, S.A., 1986. Area per molecule and distribution of water in fully hydrated dilauroylphosphatidylethanolamine bilayers. Biochemistry 25 4948-4952.

Moser, M., Marsh, D., Meier, P., Wassmer, K.-H., Kothe, G., 1989. Chain configuration and flexibility gradient in phospholipid membranes. Comparison between spinlabel electron spin resonance and deuteron nuclear magnetic resonance, and identification of new conformations. Biophys. J. 55, 111-123.

Müller, A., Lonsdale, K., 1948. The low-temperature form of $\mathrm{C}_{18} \mathrm{H}_{38}$. Acta Crystallogr. $1,129-131$.

Nagle, J.F., Tristram-Nagle, S., 2000. Structure of lipid bilayers. Biochim. Biophys. Acta 1469, 159-195.

Nagle, J.F., Wiener, M.C., 1988. Structure of fully hydrated bilayer dispersions Biochim. Biophys. Acta 942, 1-10.

Nagle, J.F., Wilkinson, D.A., 1978. Lecithin bilayers - density measurements and molecular interactions. Biophys. J. 23, 159-175.

Nahringbauer, I., 1970. Hydrogen bond studies. 39. Reinvestigation of the crystal structure of acetic acid (at $+5^{\circ} \mathrm{C}$ and $-190^{\circ} \mathrm{C}$ ). Act. Chem. Scand $24,453-462$.

Nyburg, S.C., Pickard, F.M., Norman, N., 1976. X-ray powder diagrams of certain n-alkanes: Corrigenda and extension. Acta Cryst. Sect. B 32, 2289-2293.

Pabst, G., Grage, S.L., Danner-Pongratz, S., Jing, W., Ulrich, A.S., Watts, A., Lohner K., Hickel, A., 2008. Membrane thickening by the antimicrobial peptide PGLa. Biophys. J. 95, 5779-5788.

Pascher, I., Lundmark, M., Nyholm, P.-G., Sundell, S., 1992. Crystal structures of membrane lipids. Biochim. Biophys. Acta 1113, 339-373.

Pascher, I., Sundell, S., 1977. Molecular arrangements in sphingolipids - crystal structure of cerebroside. Chem. Phys. Lipids 20,175-191.

Pascher, I., Sundell, S., 1985. Interactions and space requirements of the phosphate head group in membrane lipids. The crystal structure of disodium lysophosphatidate dihydrate. Chem. Phys. Lipids 37, 241-250.

Pascher, I., Sundell, S., 1986. Membrane lipids: preferred conformational states and their interplay. The crystal structure of dilauroylphosphatidyl-N,Ndimethylethanolamine. Biochim. Biophys. Acta 855, 68-78.

Pascher, I., Sundell, S., 1992. Molecular arrangements in sphingolipids - crystal structure of the ceramide $N$-(2D,3D-dihydroxyoctadecanoyl)-phytosphingosine. Chem. Phys. Lipids 62, 79-86.

Pascher, I., Sundell, S., Eibl, H., Harlos, K., 1984. Interactions and space requirement of the phosphate head group of membrane lipids - the single crystal structures of a triclinic and a monoclinic form of hexadecyl-2-deoxyglycerophosphoric acid monohydrate. Chem. Phys. Lipids 35, 103-115.

Pascher, I., Sundell, S., Eibl, H., Harlos, K., 1986. The single-crystal structure of octadecyl-2-methyl-glycerophosphocholine monohydrate - a multilamellar structure with interdigitating head groups and hydrocarbon chains. Chem. Phys Lipids 39, 53-64.

Pascher, I., Sundell, S., Harlos, K., Eibl, H. 1987. Conformation and packing properties of membrane lipids: The crystal structure of sodium dimyristoylphosphatidylglycerol. Biochim. Biophys. Acta 896, 77-88.

Pascher, I., Sundell, S., Hauser, H., 1981a. Glycerol conformation and molecular packing of membrane lipids. The crystal structure of 2,3-dilauroyl-D-glycerol. J. Mol. Biol. 153, 791-806. 
Pascher, I., Sundell, S., Hauser, H., 1981b. Polar group interaction and molecular packing of membrane lipids - the crystal structure of lysophosphatidylethanolamine. J. Mol. Biol 153, 807-824.

Pearson, R.H., Pascher, I., 1979. The molecular structure of lecithin dihydrate. Nature (Lond.) 281, 499-501.

Petrache, H.I., Tristram-Nagle, S., Gawrisch, K., Harries, D., Parsegian, V.A., Nagle, J.F., 2004. Structure and fluctuations of charged phosphatidylserine bilayers in the absence of salt. Biophys. J. 86, 1574-1586.

Rama Krishna, Y.V.S., Marsh, D., 1990. Spin label ESR and ${ }^{31} \mathrm{P}-\mathrm{NMR}$ studies of the cubic and inverted hexagonal phases of dimyristoylphosphatidylcholine/myristic acid (1:2, mol/mol) mixtures. Biochim. Biophys. Acta 1024, 89-94.

Reiss-Husson, F., Luzzati, V., 1964. Structure of micellar solutions of some amphiphilic compounds in pure water as determined by absolute small-angle X-ray scattering techniques. J. Phys. Chem. 68, 3504-3511.

Requena, J., Haydon, D.A., 1975. Van der Waals forces in oil-water systems from study of thin lipid films. 2. Dependence of van der Waals free energy of thinning on film composition and structure. Proc. R. Soc. A 347, 161-177.

Rossini, F.D., Pitzer, K.S., Arnett, R.L., Braun, R.M., Pimentel, G.C., 1953. Selected Values of Physical and Thermodynamic Properties of Hydrocarbons and Related Compounds. Carnegie Press, Pittsburgh.

Schmidt, G., Knoll, W., 1985. Densitometric characterization of aqueous lipid dispersions. Ber. Bunsenges. Phys. Chem. 89, 36-45.

Schorn, K., Marsh, D., 1996a. Lipid chain dynamics and molecular location of diacylglycerol in hydrated binary mixtures with phosphatidylcholine: spin label ESR studies. Biochemistry 35, 3831-3836.

Schorn, K., Marsh, D., 1996b. Lipid chain dynamics in diacylglycerolphosphatidylcholine mixtures studied by slow-motional simulations of spin label ESR spectra. Chem. Phys. Lipids 82, 7-14.

Seddon, J.M., Cevc, G., Kaye, R.D., Marsh, D., 1984. X-ray diffraction study of the polymorphism of hydrated diacyl- and dialkylphosphatidylethanolamines. Biochemistry 23, 2634-2644.

Small, D.M., 1986. In: Hanahan, D. (Ed.), Handbook of Lipid Research. The Physical Chemistry of Lipids, Vol. 4. Plenum Press, New York, 672 pp.
Smith, A.E., 1953. The crystal structure of the normal paraffin hydrocarbons. J. Chem. Phys. 21, 2229-2231.

Sun, W.-J., Knewtson, R.M., Worthington, C.R., Tristram-Nagle, S., Zhang, R., Nagle, J.F., 1994. Order and disorder in fully hydrated unoriented bilayers of gel phase dipalmitoylphosphatidylcholine. Phys. Rev. E 49, 4665-4676.

Sun, W.J., Tristram-Nagle, S., Suter, R.M., Nagle, J.F., 1996. Structure of gel phase saturated lecithin bilayers: temperature and chain length dependence. Biophys. J. 71, 885-891.

Swamy, M.J., Marsh, D., 1994. Spin-label electron spin resonance studies on the dynamics of the different phases of $N$-biotinylphosphatidylethanolamines. Biochemistry $33,11656-11663$.

Tardieu, A., Luzzati, V., Reman, F.C., 1973. Structure and polymorphism of the hydrocarbon chains of lipids: a study of lecithin-water phases. J. Mol. Biol. 75, 711-713.

Tristram-Nagle, S., Liu, Y., Legleiter, J., Nagle, J.F., 2002. Structure of gel phase DMPC determined by X-ray diffraction. Biophys. J. 83, 3324-3326.

Uhríková, D., Rybár, P., Hianik, T., Balgavý, P., 2007. Component volumes of unsaturated phosphatidylcholines in fluid bilayers: a densitometric study. Chem. Phys. Lipids 145, 97-105.

Ul-haque, M., Caughlan, C.N., 1966. Crystal and molecular structure of disodium $\beta$ glycerolphosphate pentahydrate $\left(\mathrm{Na}_{2} \mathrm{PO}_{4} \mathrm{C}_{3} \mathrm{H}_{5}(\mathrm{OH})_{2} \cdot 5 \mathrm{H}_{2} \mathrm{O}\right)$. J. Am. Chem. Soc. 88, 4124-4128.

Ulrich-Bott, B., Wiegandt, H., 1984. Micellar properties of glycosphingolipids in aqueous media. J. Lipid Res. 25, 1233-1245.

Wiener, M.C., Suter, R.M., Nagle, J.F., 1989. Structure of the fully hydrated gel phase of dipalmitoylphosphatidylcholine. Biophys. J. 55, 315-325.

Wiener, M.C., White, S.H., 1992. Structure of a fluid dioleoylphosphatidylcholine bilayer determined by joint refinement of X-ray and neutron diffraction data. II. Distribution and packing of terminal methyl groups. Biophys. J. 61, 428-433.

Wilkinson, D.A., Tirrell, D.A., Turek, A.B., McIntosh, T.J., 1987. Tris buffer causes acyl chain interdigitation in phosphatidylglycerol. Biochim. Biophys. Acta 905, 447-453.

Yang, C.P., Wiener, M.C., Lewis, R.N.A.H., McElhaney, R.N., Nagle, J.F., 1986. Dilatometric studies of isobranched phosphatidylcholines. Biochim. Biophys. Acta 863, 33-44. 